\title{
Construction of high-density linkage maps for mapping quantitative trait loci for multiple traits in field pea (Pisum sativum L.)
}

Krishna K. Gali', Yong Liu', Anoop Sindhu², Marwan Diapari, Arun S. K. Shunmugam, Gene Arganosa', Ketema Daba', Carolyn Caron ${ }^{1}$, Reddy V. B. Lachagari ${ }^{5}$, Bunyamin Tar'an ${ }^{1}$ and Thomas D. Warkentin ${ }^{1 *}$ (D)

\begin{abstract}
Background: The objective of this research was to map quantitative trait loci (QTLs) of multiple traits of breeding importance in pea (Pisum sativum L.). Three recombinant inbred line (RIL) populations, PR-02 (Orb x CDC Striker), PR-07 (Carerra x CDC Striker) and PR-15 (1-2347-144 x CDC Meadow) were phenotyped for agronomic and seed quality traits under field conditions over multiple environments in Saskatchewan, Canada. The mapping populations were genotyped using genotyping-by-sequencing (GBS) method for simultaneous single nucleotide polymorphism (SNP) discovery and construction of high-density linkage maps.

Results: After filtering for read depth, segregation distortion, and missing values, 2234, 3389 and 3541 single nucleotide polymorphism (SNP) markers identified by GBS in PR-02, PR-07 and PR-15, respectively, were used for construction of genetic linkage maps. Genetic linkage groups were assigned by anchoring to SNP markers previously positioned on these linkage maps. PR-02, PR-07 and PR-15 genetic maps represented 527, 675 and 609 non-redundant loci, and cover map distances of 951.9, 1008.8 and $914.2 \mathrm{CM}$, respectively. Based on phenotyping of the three mapping populations in multiple environments, 375 QTLs were identified for important traits including days to flowering, days to maturity, lodging resistance, Mycosphaerella blight resistance, seed weight, grain yield, acid and neutral detergent fiber concentration, seed starch concentration, seed shape, seed dimpling, and concentration of seed iron, selenium and zinc. Of all the QTLs identified, the most significant in terms of explained percentage of maximum phenotypic variance $\left(P V_{\max }\right)$ and occurrence in multiple environments were the QTLs for days to flowering $\left(P V_{\max }=47.9 \%\right)$, plant height $\left(P V_{\max }=65.1 \%\right)$, lodging resistance $\left(P V_{\max }=35.3 \%\right)$, grain yield $\left(P V_{\max }=54.2 \%\right)$, seed iron concentration $\left(P V_{\max }=27.4 \%\right)$, and seed zinc concentration ( $\left.P V_{\max }=43.2 \%\right)$.
\end{abstract}

Conclusion: We have identified highly significant and reproducible QTLs for several agronomic and seed quality traits of breeding importance in pea. The QTLs identified will be the basis for fine mapping candidate genes, while some of the markers linked to the highly significant QTLs are useful for immediate breeding applications.

Keywords: Pea, Pisum sativum L., Quantitative trait loci

\footnotetext{
* Correspondence: tom.warkentin@usask.ca

${ }^{1}$ Crop Development Centre, Department of Plant Sciences, 51 Campus Drive,

University of Saskatchewan, Saskatoon, SK, Canada

Full list of author information is available at the end of the article
}

(c) The Author(s). 2018 Open Access This article is distributed under the terms of the Creative Commons Attribution 4.0 International License (http://creativecommons.org/licenses/by/4.0/), which permits unrestricted use, distribution, and reproduction in any medium, provided you give appropriate credit to the original author(s) and the source, provide a link to the Creative Commons license, and indicate if changes were made. The Creative Commons Public Domain Dedication waiver (http://creativecommons.org/publicdomain/zero/1.0/) applies to the data made available in this article, unless otherwise stated. 


\section{Background}

Pea (Pisum sativum L.) is one of the most widely grown pulse crops in the world, along with common bean and chickpea. Pea seeds are highly nutritious as they contain approximately $25 \%$ protein, slowly digestible carbohydrates, and a rich array of vitamins, minerals, and phytochemicals [1]. Key pea breeding objectives include increasing resistance to biotic and abiotic stresses, as well as increasing grain yield, lodging resistance, and seed mineral concentration [2]. Breeding progress over the past two decades has led to improvement in grain yield in the order of $2 \%$ per year, as well as improvements in lodging resistance, biotic stress tolerance, seed protein concentration, and improved plant architecture, in particular with the wide adoption of the afila gene for the semileafless trait (reviewed by [3]).

Molecular markers including single nucleotide polymorphisms (SNPs), simple sequence repeats (SSRs) and other markers have been used to study the genetic variation within Pisum. These markers were useful for the construction of linkage maps to provide frameworks for identification of quantitative trait loci (QTLs) and trait-linked markers related to many important traits including resistance to diseases such as powdery mildew, Fusarium wilt, Ascochyta blight and rust, lodging resistance, time to flowering, seed mineral and protein concentration (reviewed by [2-5]), and validation of some of the identified QTLs (eg. [6]). However, the QTLs identified using these markers had large confidence intervals due to low resolution genetic maps and uneven distribution of markers. Therefore, development of high density genetic linkage maps is important for QTL identification and marker-assisted breeding.

SNP markers have a wide occurrence across the genome, thus are an ideal choice for construction of high density linkage maps and identification of markers closely linked to traits [7]. With the use of next generation sequencing, many SNPs have been detected in many different crops, and these SNPs are useful to discriminate between closely related individuals, fine mapping of QTLs, characterization of genes contributing to quantitatively inherited traits, and to distinguish between closely related QTLs of different traits [8, 9]. In pea, 20,008 and 248,617 SNPs have been identified by genome wide transcriptome sequencing [10] and DNA sequencing [2] of diversity panels, respectively. These SNPs have been used to develop 1536 [10] and 13,200 [2] SNP arrays, and to generate linkage maps and association mapping analyses in different pea populations. Some of these maps have been combined to build consensus maps to increase mapping resolution and genome coverage [10-12]. Genotyping-by-sequencing (GBS) method allows simultaneous SNP discovery and genotyping of populations [13]. In the last few years,
GBS has been used for SNP identification, generation of high-density linkage maps, and fine mapping of QTLs for various traits in a diverse range of crops [14-16], including mapping of Ascochyta blight resistance [17] and components of heat stress resistance [18] in pea. Recently, Boutet et al. [19] identified 419,024 SNPs using HiSeq whole genome sequencing of four pea lines. A subset of 64,263 markers were genotyped in a subpopulation of 48 RILs of a mapping population using GBS and a genetic linkage map was constructed [19]. The currently available sequencing and genotyping technologies can be used to accelerate breeding for key traits by exploiting the diversity of pea germplasm, identification of trait-linked markers, and their use in marker-assisted selection (MAS).

Bi-parental mapping populations are useful for high precision mapping of various traits [20], and the markers thus identified have been used for MAS. Determining marker-phenotype association for complex traits is a difficult task because of the number of underlying QTLs, QTL x Environment interaction, and epistasis [21]. Therefore, multi-location, multi-year replicated field trials are required to characterize QTLs associated with complex traits. QTLs responsible for the genetic control of various biotic stresses, seed protein content, lodging resistance, and seed nutrition in pea have been reported $[2,6,22]$. The current study was designed to identify QTLs for Mycosphaerella blight resistance, lodging resistance, agronomic traits, seed mineral concentration, fibre concentration, and grain yield using three bi-parental populations of pea, repeated phenotyping at two different field locations, and high density genetic linkage mapping by GBS, for MAS in pea breeding.

\section{Methods}

\section{Plant materials}

Three recombinant inbred populations (RILs) of pea, namely, PR-02 derived from the cross Orb/CDC Striker, PR-07 derived from the cross Carrera/CDC Striker, and PR-15 derived from the cross 1-2347-144/CDC Meadow, each consisting of 94 individuals were used for phenotyping and genotyping. Cultivar Orb was developed by Sharpes (UK), cultivar Carrera was developed by Limagrain (The Netherlands), cultivar CDC Striker [23], cultivar CDC Meadow [24], and breeding line 1-2347-144 [25] were developed by the Crop Development Centre, University of Saskatchewan, Canada. All the RIL populations were developed at the Crop Development Centre, University of Saskatchewan using single seed descent to the F5 generation. A single seed of each RIL at $F_{9}$ generation was used for genotyping, and PR-02 and PR-07 RILs of $F_{6}$ to $F_{8}$ generations, and PR-15 RILs of $F_{7}$ and $F_{8}$ generations, were used for phenotyping. 


\section{Genotyping-by-sequencing (GBS)}

RIL populations were genotyped using GBS according to the protocol described in detail by Elshire et al. [13].

\section{Library preparation and sequencing}

Young leaf tissue harvested and freeze dried from 14-day old seedlings was used for DNA extraction using the QIAGEN DNeasy 96 plant kit. DNA was quantified using picogreen and DNA concentration of each RIL was normalized to $20 \mathrm{ng} / \mu \mathrm{l}$. Two hundred $\mathrm{ng}$ of DNA of each individual was digested with restriction enzymes Pst I and MspI, and ligated with unique 4-8 sequence barcode adapters. From the $40 \mu \mathrm{L}$ individual ligation reaction mixture, five $\mu \mathrm{L}$ of adapter ligated DNA of 47 RILs and $15 \mu \mathrm{L}$ of adapter ligated DNA of each parent were pooled separately in a single tube to produce 49-plex libraries. The pooled DNA was PCR-amplified using sequencing primer followed by purification using a QIAGEN PCR purification kit. The purified DNA library was quantified using a Bioanalyzer (Agilent Technologies) and GBS 49-plex libraries were sequenced on a single lane of Illumina $\mathrm{HiSeq}^{\mathrm{T}}{ }^{\mathrm{T}} 2500$ platform (Illumina ${ }^{\circ}$ Inc., San Diego, CA, USA) using V4 sequencing chemistry at SickKids Hospital, Toronto, Canada.

\section{SNP variant calling}

From the Illumina data of each library, sequences were assigned to individual samples based on the 4 to 8 base pair barcode adapters ligated to individual DNA using in-house Perl scripts. Following deconvolution, barcode sequences were removed from the sequences, and the reads were trimmed for quality using the read trimming tool Trimmomatic- 0.33 . To discover polymorphisms, filtered reads were mapped to the draft genome assembly provided through the international pea genome sequencing consortium (unpublished) using the sequence alignment tool Bowtie 2 version 2.2.5. Samtools-1.1 and BCFtools-1.1 were utilized to call variants and output them in variant call format (VCF) format.

\section{Construction of genetic linkage maps}

Polymorphic SNP markers from the previously published linkage maps of the three RIL populations (Sindhu et al., 2014) were included in the linkage analysis along with the polymorphic markers identified by GBS in the current study. Polymorphic markers with less than $15 \%$ of missing data per sample were used to construct the genetic linkage maps. The segregation distortion of each marker was assessed by Chi-square test and markers with a distortion probability of greater than $90 \%$ were omitted from the linkage analysis. The linkage analysis was conducted using MstMap program with a logarithm of odds (LOD) value of 9.0 and Kosambi mapping function $[26,27]$.

\section{Phenotyping of mapping populations}

PR-02 and PR-07 were phenotyped in two location field trials over three years, and PR-15 was phenotyped in two location field trials over two years, from 2010 to 2013 (Additional files 1, 2 and 3). The mapping populations were evaluated for agronomic traits plant height, days to flower, days to maturity and lodging (1-9 rating scale, $1=$ no lodging to $9=$ completely lodged at physiological maturity), grain yield and 1000 seed weight according to methods reported in Warkentin et al. [3]. PR-02 and PR-07 were evaluated for seed mineral concentration ( $\mathrm{Fe}, \mathrm{Zn}$ and $\mathrm{Se}$ ) according to methods reported in Diapari et al. [28]. PR-07 was evaluated for acid detergent fiber, neutral detergent fiber, and starch concentration according to methods reported in Arganosa et al. [29]. PR-15 was evaluated for seed phytate concentration according to the methods reported in Warkentin et al. [25]. PR-02 and PR-07 were evaluated for Mycosphaerella blight severity on a $0-9$ rating scale $(0=$ no disease to $9=$ completely blighted $)$ from mid-flowering to physiological maturity stages according to Jha et al. [30], and the area and under disease progress curve (AUDPC) was calculated. Seed shape $(1=$ completely round to $5=$ blocky) and seed dimpling (percent of seeds with dimpled seed coat) were evaluated according to the methods reported in Ubayasena et al. [31].

The two locations used for field trials were Sutherland (near the city of Saskatoon) $\left(52^{\circ} 12^{\prime} \mathrm{N}, 106^{\circ} 63^{\prime} \mathrm{W}\right.$ W; Dark Brown Chernozem) and Rosthern $\left(52^{\circ} 66^{\prime} \mathrm{N}, 106^{\circ} 33^{\prime} \mathrm{W}\right.$; Orthic Black Chernozem) in Saskatchewan, Canada. At each location, the RILs were planted in three row plots with $30 \mathrm{~cm}$ row spacing, $1 \mathrm{~m}$ row length, at a seeding rate of 75 seeds per plot in a randomized complete block design, which was fully replicated two times. Agronomic best management practices as per provincial government and pulse grower manuals for field pea production in Saskatchewan were utilized including appropriate seeding dates, seeding methods, weed control, and harvest methods. The frequency distribution of the trait measurements in each population were tested for normality by the Shapiro-Wilk test [32]. In case the W value was low, the trait was removed from further analysis. ANOVA was conducted for each trait in each location using SAS Mixed Procedure (SAS Institute, 2015). Pearson correlation coefficient values were calculated to determine the correlation of traits measured in each population.

\section{QTL mapping}

The phenotypic means by location for each trait were used for QTL mapping. QTL mapping was performed using composite interval mapping (CIM) using QTL Cartographer v2.5 [33]. To declare a QTL, the threshold 
for each search was obtained from 1000 permutations with a significance level of 0.05 .

\section{Results}

\section{Genotyping-by-sequencing (GBS)}

In all of the sequencing runs of 49-plex libraries approximately 225 million raw reads per lane were obtained from sequencing on Illumina HiSeq 2500 platform. Across the three populations, the average read count obtained per RIL was 3.9-4.6 million and $84 \%$ of the reads survived after trimming for quality. The trimmed reads were mapped to the reference genome and the number of mapped reads per RIL in PR-02, PR-07 and PR-15 were 3.24, 2.42 and 2.48 million, respectively (Table 1 ).

\section{Genetic linkage mapping}

Of the $>25,000$ SNPs identified by GBS in each RIL population, after filtering for read depth of 5 , percentage of missing values as less than 15\%, Chi-square value of $>0.1$ probability for segregation distortion, 2066, 3023, and 3444 SNPs were used to construct genetic linkage maps of PR-02, PR-07 and PR-15, respectively. A total of 306, 366, and 337 SNP markers earlier genotyped using Illumina GoldenGate array in the same three populations (Sindhu et al. 2014) were added to the GBS data set for linkage map construction.

In PR-02, 1866 SNP markers (1560 from GBS and 306 from GoldenGate assay) formed 14 linkage groups with a map length of 951.9 centiMorgans (cM). The length of individual linkage groups ranged from 4.0 to $149.2 \mathrm{cM}$. The total number of non-redundant loci represented by the mapped SNPs are 527 with 4 to 87 loci per linkage group. The SNP markers identified through GBS represented an additional 329 loci compared to the 198 loci represented by the SNP markers identified using the GoldenGate assay (Sindhu et al. 2014). The average distance between two loci is $1.81 \mathrm{cM}$ and the maximum distance is $19.3 \mathrm{cM}$ (Fig. 1).

The PR-07 linkage map has 3355 SNP markers (2990 from GBS and 365 from the GoldenGate assay) in 15 linkage groups. These markers together represented a total map distance of $1008.8 \mathrm{cM}$ with a minimum of $7.1 \mathrm{cM}$ and a maximum of $207.0 \mathrm{cM}$ distance per linkage group. A total of 675 non-redundant loci were mapped with a minimum of 10 and maximum of 128 non-redundant loci per linkage group. The SNPs identified through GBS represented 459 non-redundant loci in addition to the 216 loci mapped from previous reported SNPs (Fig. 2).

The PR-15 linkage map has 3408 SNPs (3077 SNPs from the current GBS and 337 from the GoldenGate assay) grouped into 12 linkage groups. The total map length is $914.2 \mathrm{cM}$ with individual linkage groups ranging from $20.0 \mathrm{cM}$ to $153.1 \mathrm{cM}$. The map represented 609 non-redundant loci with a minimum of 16 and maximum of 94 per linkage group. Of the total non-redundant loci mapped, 417 are represented by the SNPs identified by GBS and 192 have a representation of earlier genotyped SNPs. The average distance between the non-redundant loci across the linkage groups is $1.5 \mathrm{cM}$ (Fig. 3).

\section{Phenotypic data}

Phenotypic data collected for PR-02, PR-07, and PR-15 are summarized in Additional files 1, 2, and 3, respectively. Data for all traits were tested for normality using the Shapiro-Wilk test. In the vast majority of cases the $\mathrm{W}$ value was $>0.90$. In cases in which the $\mathrm{W}$ value was low, the traits were removed from further analysis.

All three populations were assessed for days to flowering. In the case of PR-02 and PR-15, RILs flowered within a relatively narrow range, while this range was generally greater, approximately one week, for PR-07 depending on the station/year. The range in days to maturity was wider for all three RIL populations, generally from one to two weeks. Substantial variation was noted in all three RIL populations for plant height and lodging score, with greatest variation in PR-07 for both traits. Similarly for grain yield, substantial variation was noted in all three RIL populations, with somewhat greater range in variation noted in PR-07 and PR-15. Mean yield ranged from 195 to $516 \mathrm{~g} \mathrm{~m}^{-2}$ in PR-02, 266-536 $\mathrm{g} \mathrm{m}^{-2}$ in PR-07, and 307-858 $\mathrm{g} \mathrm{m}^{-2}$ in PR-15. Mean commercial yield of field pea in western Canada is approximately $270 \mathrm{~g} \mathrm{~m}^{-2}$, indicating that the three RIL populations have good yield potential, and that the field trials reported here were conducted under conditions favourable for expression of yield potential. The Mycosphaerella

Table 1 Summary of average read count from sequencing of three mapping populations (49-plex libraries) using genotyping-bysequencing method

\begin{tabular}{lllll}
\hline RIL Population & \multicolumn{2}{l}{ Average number of reads/RIL (millions) } \\
\cline { 2 - 5 } & Read count & $\begin{array}{l}\text { Reads surviving } \\
\text { after trimming }\end{array}$ & No. of unique reads & $\begin{array}{l}\text { Total No. of reads mapped } \\
\text { to draft genome }\end{array}$ \\
\hline PR-2 (Orb x CDC Striker) & 4.6 & 4.02 & $1.15(28.7 \%)$ & $3.24(80.8 \%)$ \\
PR-7 (Carerra x CDC Striker) & 4.0 & 3.15 & $1.08(34.3 \%)$ & $2.42(76.8 \%)$ \\
PR-15 (1-2347-144 x CDC Meadow) & 3.9 & 3.19 & $1.19(37.3 \%)$ & $2.48(77.8 \%)$ \\
\hline
\end{tabular}




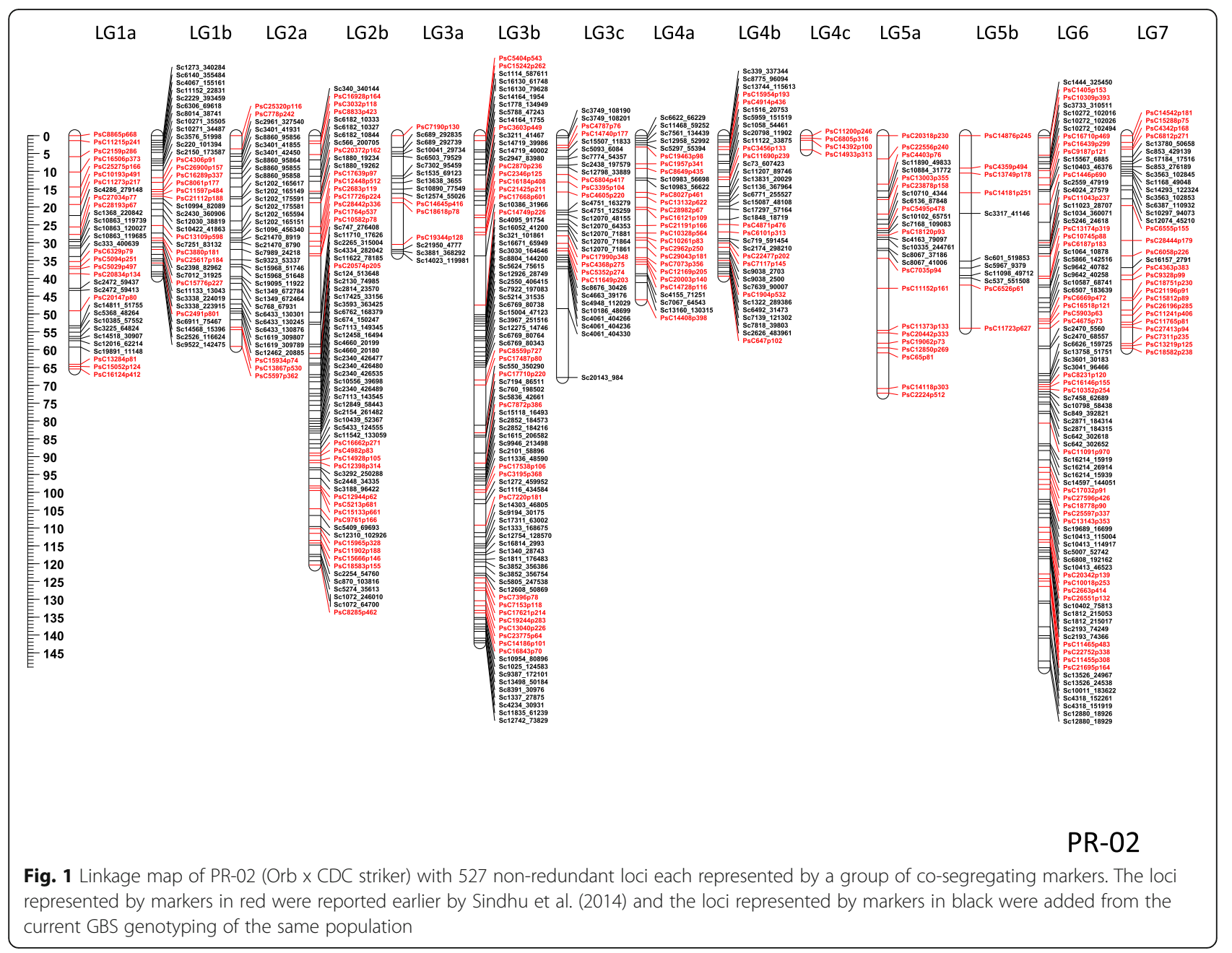

blight resistance, reported as AUDPC ranged from 156 to 208 in PR-07 RILs measured at all six station/years.

Several post-harvest seed quality traits were assessed in some of the RIL populations. Substantial variation was noted in 1000 seed weight, as well as protein, iron, zinc, and selenium concentration in PR-02 and PR-07. In the case of seed selenium concentration, the range in variation among RILs in PR-02 and PR-07 was greater at the Sutherland (Saskatoon) site than at the Rosthern site in each year. Peas grown in the Saskatoon region are known to have generally greater selenium concentration than peas grown in the Rosthern region [34], and that was also observed in this research. Acid detergent fiber, neutral detergent fiber, and starch concentrations of PR-07 lines varied significantly at each station/year assessed, as did seed coat dimpling and seed shape. PR-15 was developed from the cross between a low phytate and a normal phytate parent, and as expected, lines differed significantly for this trait at each station/year assessed.
Correlation analyses in the three RIL populations were presented in Additional files 4, 5, and 6. In PR-02 and PR-07, the strongest correlation was between days to flowering and days to maturity, followed by correlation between days to maturity and yield in PR-02, and Mycosphaerella blight severity and lodging in PR-07. In PR-15, the strongest correlation observed was between plant height and yield, followed by plant height and days to maturity, days to maturity and yield, and days to flowering and lodging resistance.

\section{QTL detection in pea mapping populations}

Across the three pea mapping populations, a total of 375 QTLs, i.e., 96 in PR-02, 225 in PR-07, and 54 in PR-15, were identified for multiple traits in multiple environments. The identified QTLs had a maximum LOD value of 23.8 and explained phenotypic variation of up to $62.9 \%$ in case of QTLs identified for plant height in PR-07. Of all the identified QTLs, 292 trait specific QTLs were detected on the same linkage group in more 


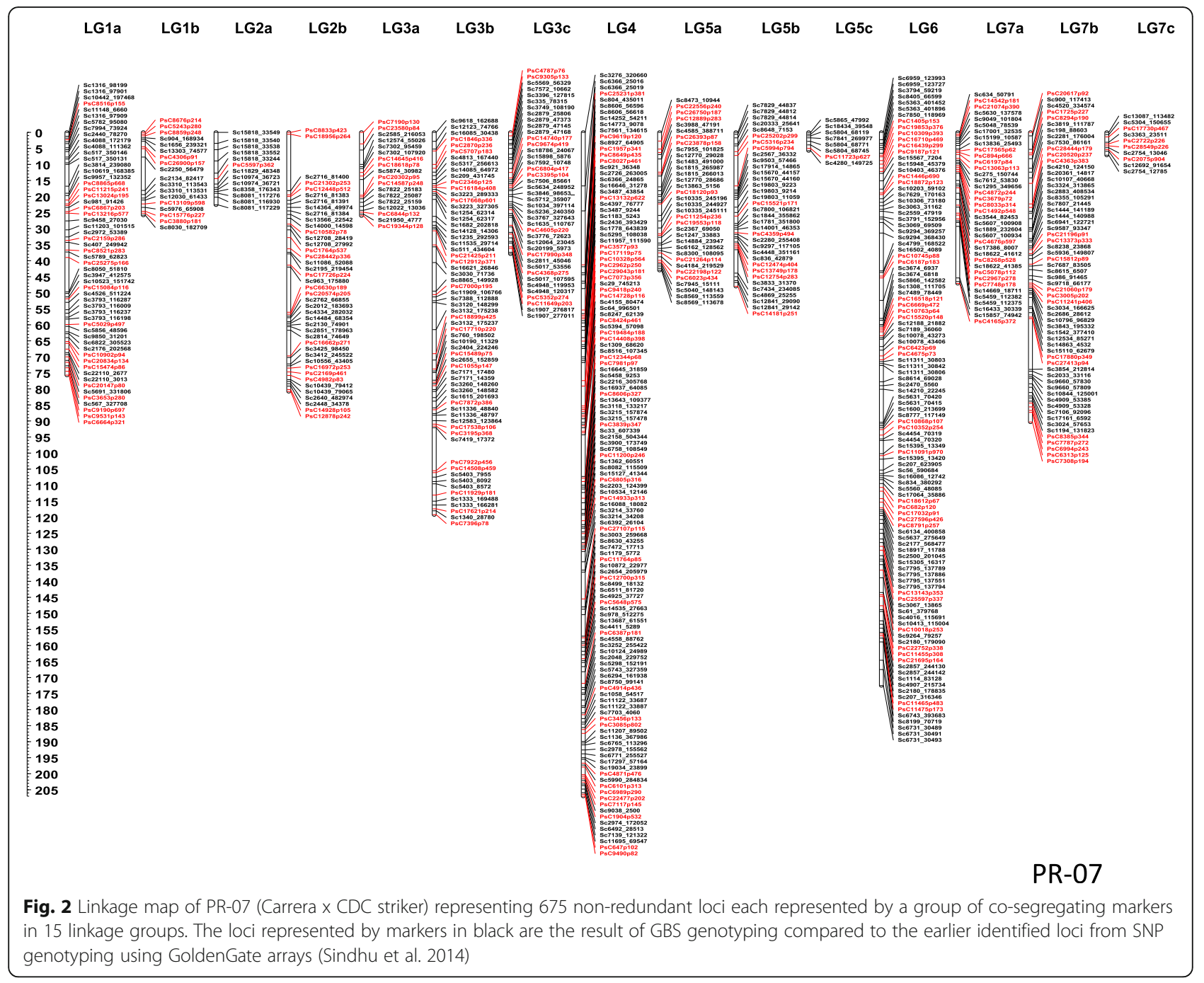

than one environment within the same population (Tables 2, 3 and 4).

\section{QTLs for agronomic traits}

QTLs for days to flowering Of the multiple QTLs identified for DTF, QTLs on LG5a and LG6 in PR-02, LG1a and LG3b in PR-07, LG3a and LG5 in PR-15 were identified in multiple trials (Tables 2, 3 and 4). Compared between the three populations and environments tested, the QTL on LG6 in PR-02 was significant in five of the six trials. In all the five trials, the QTL position shared a common position on the same linkage group. The LOD values of this QTL on LG6 ranged from 5.319.0 and explained a phenotypic variance of 17.9 to 47.9\% (Table 5).

QTLs for days to maturity QTLs for DTM positioned on LG3b and LG6 of PR-02 (Table 2), LG1a and LG3b of PR-07 (Table 3), and LG3a and LG5 of PR-15 (Table 4) were identified in repeated trials. QTLs on LG6 in PR-02 and LG3a in PR-15 shared a common position within these two respective linkage groups. In PR-02, the QTLs on LG6 represented a maximum LOD value of 8.4 and explained $33.4 \%$ of phenotypic variance. In the same population, the QTLs on LG3b represented a maximum LOD value of 7.7 and explained a phenotypic variance of up to $24.9 \%$ (Table 5). The maximum LOD value of the QTLs identified in PR-07 and PR-15 was 4.4 and 6.6 and these QTLs explained a phenotypic variance of 11.8 and $15.2 \%$, respectively (Tables 3 and 4). These QTLs located on LG1a in PR-07 and LG5 of PR-15 (Table 7) shared the same linkage group positions with the most significant QTLs identified for DTF.

QTLs for plant height Multiple QTLs were identified for plant height in all three mapping populations. However, the QTLs of LG3b in PR-02 and PR-07, and LG3a in PR-15 were identified in all of the trials (Tables 2, 3 and 4). These QTLs also shared linkage 


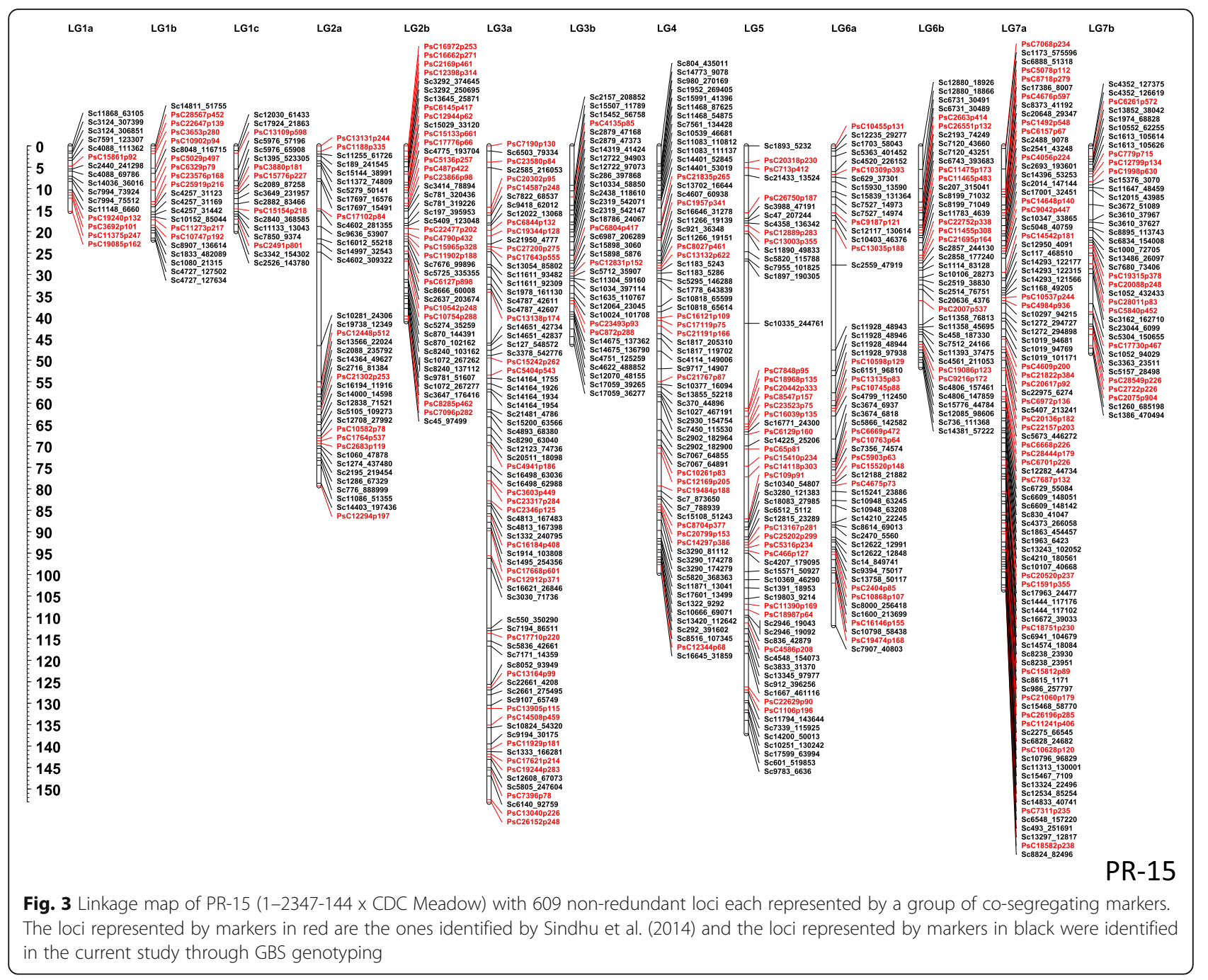

group positions between most of the trials in each population, and represented a maximum LOD value of 16.7, 23.8 and 13.0, and explained a phenotypic variance of 41.5, 62.9 and 27.4, in PR-02, PR-07 and PR-15, respectively (Tables 5, 6 and 7).

QTLs for Mycosphaerella blight resistance Mycosphaerella blight resistance was measured at four growth stages of PR-07 using a 0-9 rating scale and the scored values were used to calculate AUDPC. Of the QTLs identified on six linkage groups in six trials, the QTLs on LG3b were identified in four of the six trials (Table 3). These QTLs on LG3b shared overlapping linkage group positions in three trials, and the QTL representing this overlapping region had the maximum LOD of 8.9 and explained $26.3 \%$ of the phenotypic variance (Table 6).

QTLs for lodging resistance All three mapping populations were evaluated for lodging resistance and significant QTLs were identified in all populations on linkage groups associated with chromosome 3 . In all the populations, lodging scores measured at pod filling stage were used for QTL analysis. In PR-02, QTLs were identified on LG3b in two of the five trials (Table 2). In PR-07, QTLs on LG3b were identified in five of the six trials (Table 3). In PR-15, QTLs were identified on LG3a in two of the four trials while four other QTLs were located on different linkage groups in individual trials (Table 4). The major QTLs for lodging resistance identified on Chromosome 3 had a maximum LOD value of 8.8, 13.2 and 9.2 in PR-02, PR-07 and PR-15 populations, respectively, and these QTLs explained a phenotypic variance of up to $35.3 \%$ in PR-07 (Tables 2, 6 and 7).

QTLs for grain yield Based on six trials, multiple QTLs were identified for grain yield in PR-02, PR-07 and PR-15. QTLs were mapped on LG6 of PR-02 in five of the six trials, LG3b of PR-07 in five of the six trials, and LG3a of PR-15 in all the four trials (Tables 2, 3 and 4). In PR-02, the QTL on LG6 was located in 
Table 2 Quantitative trait loci (QTL) identified for multiple traits in PR-02 mapping population

\begin{tabular}{|c|c|c|c|c|c|c|c|c|c|c|c|c|c|c|c|}
\hline \multirow[t]{2}{*}{ Trait } & \multirow[t]{2}{*}{ Station/year } & \multicolumn{14}{|c|}{ Linkage group } \\
\hline & & LG1a & LG1b & LG2a & LG2b & LG3a & LG3b & LG3C & LG4a & LG4b & LG4C & LG5a & LG5b & LG6 & LG7 \\
\hline \multirow[t]{6}{*}{ Days to Flowering } & 2011 Sutherland & & & 4.46 & & & & & & & & & & 5.29 & \\
\hline & 2011 Rosthern & & & & & & & & & & & 3.54 & & 9.16 & \\
\hline & 2012 Sutherland & & & & & 3.6 & & & & & & & & 12.84 & \\
\hline & 2012 Rosthern & & & & & & & & & & & 3.79 & & & \\
\hline & 2013 Sutherland & & & & 5.25 & & & & & & & 3.86 & & 19.0 & \\
\hline & 2013 Rosthern & & & & & & & & & & & & & 10.63 & \\
\hline \multirow[t]{8}{*}{ Days to Maturity } & 2011 Sutherland & & & & & & 4.26 & & & & & & & 5.56 & \\
\hline & & & & & & & & & & & & & & 8.19 & \\
\hline & 2011 Rosthern & & & & & & 4.46 & & & & & & & 3.19 & \\
\hline & & & & & & & 4.8 & & & & & & & & \\
\hline & 2012 Sutherland & & & & & & & & & 5.06 & & & & & \\
\hline & 2012 Rosthern & & & & & & 7.69 & & & & & 3.06 & 6.33 & & \\
\hline & 2013 Sutherland & & & & & & & & & & & & & 5.0 & \\
\hline & 2013 Rosthern & & & 3.07 & & & & 4.1 & & & & & & 8.4 & \\
\hline \multirow[t]{7}{*}{ Plant height (cm) } & 2011 Sutherland & & & & & & 12.81 & & 6.45 & & & & & & \\
\hline & & & & & & & 8.1 & & & & & & & & \\
\hline & 2011 Rosthern & & & & & & 5.09 & & & & & & & 4.56 & \\
\hline & 2012 Sutherland & & & 6.2 & & & 5.47 & & & & & 4.05 & & & \\
\hline & & & & 4.41 & & & & & & & & & & & \\
\hline & 2012 Rosthern & & & & & & 16.71 & & & & & 4.22 & & & \\
\hline & 2013 Rosthern & 4.43 & & & & & & & & & & & & & \\
\hline \multirow[t]{6}{*}{ Lodging Resistance (1-9) } & 2011 Sutherland & & & & & & & & & & & & 3.73 & & \\
\hline & 2011 Rosthern & & & & & & 3.92 & & & & & & & & \\
\hline & & & & & & & 3.61 & & & & & & & & \\
\hline & 2012 Sutherland & & & & & & & & & & & & & & \\
\hline & 2012 Rosthern & & & & & & 8.83 & & & & & & & & \\
\hline & 2013 Rosthern & & & & & & & & & & & 4.64 & & & \\
\hline \multirow[t]{8}{*}{ Yield $\left(\mathrm{g} / \mathrm{m}^{2}\right)$} & 2011 Sutherland & & & & & & & & 22.31 & & & & & 3.09 & \\
\hline & & & & & & & & & & & & & & 3.26 & \\
\hline & 2011 Rosthern & & & & & & 3.38 & & 10.99 & & & & & 6.2 & \\
\hline & & & & & & & & & & & & & & 3.54 & \\
\hline & 2012 Sutherland & & & & & & & & & & & & & 4.73 & \\
\hline & 2012 Rosthern & & & & & & 3.2 & & 11.24 & & & & & & \\
\hline & 2013 Sutherland & & & & & & & & & & & & & 6.61 & \\
\hline & 2013 Rosthern & & & & & & & 3.48 & & & & & & 7.96 & \\
\hline \multirow[t]{2}{*}{1000 seed weight (g) } & 2011 Sutherland & 3.06 & 3.4 & & & & 3.03 & & 6.15 & & & & & 4.64 & \\
\hline & 2011 Rosthern & & & & & & 4.6 & & & 4.46 & & 5.51 & & 3.61 & \\
\hline \multirow[t]{3}{*}{ Seed protein conc. (\%) } & 2012 Sutherland & & & & & & & & & & & 3.17 & & & \\
\hline & 2013 Sutherland & & 5.00 & & & & & & 3.39 & & & & & & \\
\hline & 2013 Rosthern & & 4.97 & & & & & & 3.37 & & & & & & \\
\hline \multirow[t]{3}{*}{ Acid detergent Fiber (\%) } & 2012 Sutherland & & & & & & & & & 4.64 & & 6.86 & & & \\
\hline & 2013 Sutherland & & & & & & & & & & & & & 3.44 & 8.36 \\
\hline & 2013 Rosthern & & & & & & & & & & & & & & 8.65 \\
\hline
\end{tabular}


Table 2 Quantitative trait loci (QTL) identified for multiple traits in PR-02 mapping population (Continued)

\begin{tabular}{|c|c|c|c|c|c|c|c|c|c|c|c|c|c|c|c|}
\hline \multirow[t]{2}{*}{ Trait } & \multirow[t]{2}{*}{ Station/year } & \multicolumn{14}{|c|}{ Linkage group } \\
\hline & & LG1a & LG1b & LG2a & LG2b & LG3a & LG3b & LG3C & LG4a & LG4b & LG4C & LG5a & LG5b & LG6 & LG7 \\
\hline \multirow[t]{3}{*}{ Neutral detergent Fiber (\%) } & 2012 Sutherland & & & & & & & & & 3.53 & & 5.5 & & & \\
\hline & 2013 Sutherland & & & & & & & & & & & 5.05 & & & 6.07 \\
\hline & 2013 Rosthern & & & & & & & & & & & 5 & & & 5.96 \\
\hline \multirow[t]{3}{*}{ Seed starch conc. (\%) } & 2012 Sutherland & & & & & & & & 4.44 & & & & & & \\
\hline & 2013 Sutherland & & & & 5.54 & & & & & & & & & & \\
\hline & 2013 Rosthern & & & & 5.53 & & & & & & & & & & \\
\hline \multirow[t]{2}{*}{ Seed iron conc. (ppm) } & 2011 Sutherland & & & & 3.97 & & 7.61 & & & 3.34 & & & & & \\
\hline & 2011 Rosthern & & & & & & 6.28 & & & & & & & 3.37 & \\
\hline \multirow[t]{2}{*}{ Seed selenium conc. (ppm) } & 2011 Sutherland & & & & & & & & 11.6 & & & 3.51 & & & 3.2 \\
\hline & 2011 Rosthern & & & & & & & & & & & & & & 3.1 \\
\hline \multirow[t]{3}{*}{ Seed zinc conc. (ppm) } & 2011 Sutherland & 4.32 & & & & & & & & & & & & & \\
\hline & 2011 Rosthern & & & & & & 13.71 & & & & & & & 4.52 & \\
\hline & & & & & & & & & & & & & & 4.52 & \\
\hline
\end{tabular}

Values presented in the table represent logarithm of the odds (LOD) of the QTL peak

the same linkage group position in three of the five trials and this common QTL represented LOD values of 6.2 to 8.0 and explained phenotypic variance of 11.8 to $24.6 \%$ (Table 5). The QTL located on LG3b of PR-07 represented a maximum LOD value of 14.1 and explained $41.7 \%$ phenotypic variance. The same QTL explained a phenotypic variance of $22.6 \%$ in another trial (Table 6). The QTLs identified on LG3a of PR-15 were at different linkage group positions in all the four trials, and explained a phenotypic variance of up to $17.9 \%$, while the QTLs identified on LG1b in two of the four trials shared the linkage group position and explained phenotypic variance of 6.7 to $9.2 \%$ (Table 7 ).

QTLs for seed weight Seed weight of 1000 seeds was determined in two trials of PR-02 and QTLs have been identified on seven linkage groups, of which QTLs on LG3b and LG6 were identified in both trials (Table 2). QTLs on these two linkage groups represented a maximum LOD of 4.6 and explained a phenotypic variance of $11.6 \%$ (Table 5). For the same trait, multiple QTLs were identified on six linkage groups in PR-07, based on six trials. QTLs on three linkage groups LG3c, 4 and 6 were identified in at least four or more of the six trials tested (Table 3). The QTL on LG3c is the most significant QTL based on its overlapping linkage group positions in four of the five trials, with a maximum LOD of 15.6 and $40.0 \%$ phenotypic variance explained (Table 6).

\section{QTLs for seed quality traits}

QTLs for seed protein concentration QTLs for seed protein concentration were mapped on LG1b and LG4a of PR-02 in two of the three trials tested (Table 2). In both the trials the identified QTLs were in the same linkage group positions. The QTLs on LG1b and LG4a represented a maximum LOD value of 5.0 and 3.4, and explained the phenotypic variance of up to 15.9 and $10.3 \%$, respectively (Table 5). In PR-07, QTLs for seed protein concentration were identified on LG3b and LG7b in three and four of the six trials. These QTLs on LG3b and LG7b represented an average LOD of 3.7 and 3.4 , and explained 11.7 and $10.6 \%$ phenotypic variance, respectively (Tables 3 and 6 ).

QTLs for acid detergent fibre (ADF) In PR-02, based on three trials, QTLs were identified for ADF on four linkage groups, of which QTLs on LG7 were identified in two of the three trials (Table 2). The two QTLs on LG7 were in a common linkage group position with LOD values of 8.4 and 8.7 and explained a phenotypic variance of 28.0 and $26.2 \%$ (Table 5). In PR-07, QTLs were identified on seven linkage groups, of which QTLs on LG4 and LG7a were identified in four and three of the six trials, respectively. These QTLs which shared the same linkage group positions in two trials represented a maximum LOD of 6.6 and phenotypic variance of $18.7 \%$ (Table 6).

QTLs for neutral detergent fibre (NDF) QTLs on multiple linkage groups were identified for NDF in PR-02, of which QTLs on LG5a were identified in all the three trials tested (Table 2). These three QTLs represented LOD values from 5.0 to 5.5 and phenotypic variance of 16.2 to $19.0 \%$ (Table 5). In PR-07, NDF QTLs were identified on LG1a in all the six trials and QTLs on 
Table 3 Quantitative trait loci (QTL) identified for multiple traits in PR-07 mapping population

\begin{tabular}{|c|c|c|c|c|c|c|c|c|c|c|c|c|c|c|c|c|}
\hline \multirow[t]{2}{*}{ Trait } & \multirow[t]{2}{*}{ Station/year } & \multicolumn{15}{|c|}{ Linkage group } \\
\hline & & LG1a & LG1b & LG2a & LG2b & LG3a & LG3b & LG3C & LG4 & LG5a & LG5b & LG5C & LG6 & LG7a & LG7b & LG7C \\
\hline \multirow[t]{8}{*}{ Days to flowering } & 2010 Sutherland & 3.41 & & & & & & & & & & & & & & \\
\hline & & 4.13 & & & & & & & & & & & & & & \\
\hline & 2010 Rosthern & 5.52 & & & & & 3.09 & & 3.00 & & & & 5.10 & & & \\
\hline & 2011 Sutherland & & & & 4.72 & & 4.99 & & & & & & & & & \\
\hline & 2011 Rosthern & & & & & & 3.00 & & & & & & & & & \\
\hline & & & & & & & 4.80 & & & & & & & & & \\
\hline & 2012 Sutherland & & & & & & & & & & & & & & & \\
\hline & 2012 Rosthern & & & & & & 4.13 & & & & & & & & & \\
\hline \multirow[t]{7}{*}{ Days to Maturity } & 2010 Sutherland & 4.35 & & & & & 4.02 & & 7.90 & & & & & & & \\
\hline & 2010 Rosthern & & & & & & & 3.77 & & & & & & 3.37 & & \\
\hline & 2011 Sutherland & & & & & 4.14 & & & & & & & & 3.24 & & \\
\hline & 2011 Rosthern & & & & & & & & & & & & 4.39 & & & \\
\hline & 2012 Sutherland & 3.85 & & & & & & & & & 3.41 & & & & & \\
\hline & 2012 Rosthern & & & & & & 4.29 & & & & & & & & & \\
\hline & & & & & & & 3.54 & & & & & & & & & \\
\hline \multirow[t]{7}{*}{ Plant height $(\mathrm{cm})$} & 2010 Sutherland & & & & & & 15.74 & & 3.75 & & & & & & & \\
\hline & 2010 Rosthern & & & & 3.06 & & 23.8 & & & & & & & & & \\
\hline & 2011 Sutherland & & & & 3.3 & & 11.89 & & & & & & & & & \\
\hline & 2011 Rosthern & & & & & & 16.17 & & & & & & & & & \\
\hline & & 3.25 & & & & & & & & & & & & & & \\
\hline & 2012 Sutherland & 4.26 & & & & & 23.82 & & & & & & & 7.15 & & \\
\hline & 2012 Rosthern & & & & & & 20.52 & & & & & & & 5.09 & & \\
\hline \multirow{6}{*}{$\begin{array}{l}\text { Mycosphaerella resistance } \\
\text { (AUDPC) }\end{array}$} & 2010 Sutherland & & & & & & 3.89 & & 4.78 & & & & & & & \\
\hline & 2010 Rosthern & & & & & & & & & & 3.21 & & 5.96 & & & \\
\hline & 2011 Sutherland & & & & & & 7.76 & & 4.06 & & 6.31 & & & & & \\
\hline & 2011 Rosthern & & & & & & & & & & & & & & & \\
\hline & 2012 Sutherland & 3.23 & 3.15 & & & & 3.54 & & & & & & & & & \\
\hline & 2012 Rosthern & & & & & & 8.85 & & & & & & & 6.24 & & \\
\hline \multirow[t]{7}{*}{ Lodging resistance (1-9) } & 2010 Sutherland & & & & & & 13.19 & 3.92 & & & & & & & & \\
\hline & 2010 Rosthern & & & & & & 6.85 & & & & & & 7.21 & & & \\
\hline & & & & & & & & & & & & & 6.52 & & & \\
\hline & 2011 Sutherland & & & & & & 3.43 & & & & & & & & & \\
\hline & 2011 Rosthern & & & & & & & & & & & & & & 4.25 & \\
\hline & 2012 Sutherland & & & & 4.73 & & 4.07 & & & & & & 4.07 & & & \\
\hline & 2012 Rosthern & & & & & & 6.43 & & & & & & & 10.3 & & \\
\hline \multirow[t]{6}{*}{ Yield $\left(\mathrm{g} / \mathrm{m}^{2}\right)$} & 2010 Sutherland & & & & & & 9.24 & & 3.02 & & & & & 5.58 & & \\
\hline & 2010 Rosthern & & & & & & & & & & & & & & & \\
\hline & 2011 Sutherland & & & & & & 3.75 & & & & & & & 3.1 & & \\
\hline & 2011 Rosthern & & & & & & 14.13 & & & & & & & & & \\
\hline & 2012 Sutherland & & & & & & 6.79 & & 3.1 & & & & & 3.98 & & \\
\hline & 2012 Rosthern & & & & & & 4.02 & & 4.12 & & & & & & & \\
\hline
\end{tabular}


Table 3 Quantitative trait loci (QTL) identified for multiple traits in PR-07 mapping population (Continued)

\begin{tabular}{|c|c|c|c|c|c|c|c|c|c|c|c|c|c|c|c|c|}
\hline \multirow[t]{2}{*}{ Trait } & \multirow[t]{2}{*}{ Station/year } & \multicolumn{15}{|c|}{ Linkage group } \\
\hline & & LG1a & LG1b & LG2a & LG2b & LG3a & LG3b & LG3C & LG4 & LG5a & LG5b & LG5C & LG6 & LG7a & LG7b & LG7C \\
\hline \multirow[t]{7}{*}{1000 seed weight (g) } & 2010 Sutherland & & & & & & & 14.51 & 3.83 & 4.01 & & & 4.35 & & & \\
\hline & 2010 Rosthern & & & & & & 3.41 & 11.38 & 4.00 & & & & 3.75 & & & \\
\hline & & & & & & & & & 6.84 & & & & & & & \\
\hline & 2011 Sutherland & & & & & & 4.97 & & 3.05 & & & & & & & \\
\hline & 2011 Rosthern & & & & & & & 11.69 & 3.05 & & & & 3.33 & & & \\
\hline & 2012 Sutherland & & & & & & & 3.07 & & & & & 3.33 & 6.62 & & \\
\hline & 2012 Rosthern & & & & & & & 15.57 & & 5.58 & & & & & & \\
\hline \multirow[t]{6}{*}{ Seed protein conc. (\%) } & 2010 Sutherland & & & & & & 3.16 & & & & & & 3.15 & & & \\
\hline & 2010 Rosthern & & & & & & & & & & & & & & 3.88 & \\
\hline & 2011 Sutherland & & & & & & & & & & & & 6.21 & & 3.16 & \\
\hline & 2011 Rosthern & 3.22 & & 3.42 & 6.51 & & 3.84 & 6.01 & & & & & & 4.56 & & \\
\hline & 2012 Sutherland & 3.98 & & & & & & & & & & & & 4.83 & 3.14 & \\
\hline & 2012 Rosthern & & & & & & 4.08 & & & & 3.11 & & & & & \\
\hline \multirow[t]{7}{*}{ Acid detergent fibre (\%) } & 2010 Sutherland & & & & & & & & & & & & 3.84 & & & \\
\hline & 2010 Rosthern & 15.74 & & & & & & & 6.42 & & & & & & & \\
\hline & & & & & & & & & 6.55 & & & & & & & \\
\hline & 2011 Sutherland & & & & & & 10.1 & & 4.74 & & & & & 4.95 & & \\
\hline & 2011 Rosthern & & & & & & 3.87 & & 4.92 & & & & & 5.15 & & \\
\hline & 2012 Sutherland & 12.07 & & & 3.2 & & & & & & & & 3.39 & 5.32 & & \\
\hline & 2012 Rosthern & & & & 4.05 & & & & 6.22 & & & & 3.18 & & & 3.41 \\
\hline \multirow[t]{7}{*}{ Neutral detergent fibre (\%) } & 2010 Sutherland & 3.72 & & & 8.61 & & & & & & & & & & & \\
\hline & 2010 Rosthern & 4.76 & & & & & & & & & & & & & & \\
\hline & 2011 Sutherland & 7.25 & & & & & 7.44 & & 5.97 & & & & & 5.05 & & \\
\hline & & 3.32 & & & & & & & & & & & & & & \\
\hline & 2011 Rosthern & 13.61 & & & & & & & 5.84 & & & & & 3.63 & & \\
\hline & 2012 Sutherland & 19.46 & & & & & & & 6.95 & & 3.05 & & & 5.12 & & \\
\hline & 2012 Rosthern & 14.72 & & & & & & & 6.94 & & & & & & & \\
\hline \multirow[t]{8}{*}{ Seed starch conc. (\%) } & 2010 Sutherland & & & & & & & & & & & & & & & \\
\hline & 2010 Rosthern & & & & & & 4.03 & & & & & & & 3.33 & & \\
\hline & 2011 Sutherland & 6.09 & & & & & & 4.39 & & & & & & & & \\
\hline & & 5.03 & & & & & & & & & & & & & & \\
\hline & 2011 Rosthern & 6 & & & & & 7.05 & 3.4 & & & & & & 8.39 & & \\
\hline & 2012 Sutherland & 7.57 & & & & & 3.27 & 4.73 & & & & & & 6.6 & & \\
\hline & 2012 Rosthern & 5.79 & & & & & & & & & & & & & & \\
\hline & 2012 Rosthern & 7.56 & & & & & 6.37 & 3.76 & & & & & & 3.56 & & \\
\hline \multirow[t]{7}{*}{ Seed iron conc. (ppm) } & 2010 Sutherland & & & & & & 4.13 & & & & & & & 4.22 & & \\
\hline & 2010 Rosthern & & & & & & 10.14 & & 3.62 & & & & & & & \\
\hline & & & & & & & 5.84 & & & & & & & & & \\
\hline & 2011 Sutherland & & & & & & 2.89 & & 7.14 & & & & & & & \\
\hline & 2011 Rosthern & & & & & & 4.56 & & & & & 3.03 & & & & \\
\hline & 2012 Sutherland & & & & & & 4.04 & & & & 3.28 & & & & & \\
\hline & 2012 Rosthern & & & & & 3.18 & 10.05 & & & & & & & 6.93 & & \\
\hline
\end{tabular}


Table 3 Quantitative trait loci (QTL) identified for multiple traits in PR-07 mapping population (Continued)

\begin{tabular}{|c|c|c|c|c|c|c|c|c|c|c|c|c|c|c|c|}
\hline \multirow[t]{2}{*}{ Trait } & \multirow[t]{2}{*}{ Station/year } & \multicolumn{14}{|c|}{ Linkage group } \\
\hline & & LG1a & LG1b & LG2a & LG2b & LG3a & LG3b & LG3C & LG4 & LG5a & LG5b & LG5C & LG6 & LG7a & LG7b LG7C \\
\hline \multirow[t]{8}{*}{ Seed selenium conc. (ppm) } & 2010 Sutherland & & & & 3.65 & & & & & 3.68 & & & & & \\
\hline & 2010 Rosthern & & & & & & & & & & 3.08 & & & & \\
\hline & & & & & & & & & & & 4.51 & & & & \\
\hline & 2011 Sutherland & & & & & & & & 3.12 & & & & & 3.29 & \\
\hline & & & & & & & & & 3.81 & & & & & & \\
\hline & 2011 Rosthern & & & & & & & & & & & & & & 4.32 \\
\hline & 2012 Sutherland & & & & & & & & & & 4.15 & & & & \\
\hline & 2012 Rosthern & & & & & & & & & & & & & & \\
\hline \multirow[t]{9}{*}{ Seed zinc conc. (ppm) } & 2010 Sutherland & & & & & & 4.48 & & & & & & & 5.85 & \\
\hline & & & & & & & 17.3 & & & & & & & & \\
\hline & 2010 Rosthern & & & & & & 17.11 & & & & & & & 3.67 & \\
\hline & 2011 Sutherland & & 4.44 & & & & 6.61 & & & & & & & & \\
\hline & 2011 Rosthern & & & & & & 4.09 & & & & & & & & \\
\hline & & & & & & & 12.09 & & & & & & & & \\
\hline & 2012 Sutherland & & & & 4.61 & & & & 4.9 & & & & & & \\
\hline & 2012 Rosthern & 3.46 & & & & & 4.48 & & & & & & & & \\
\hline & & & & & & & 8.56 & & & & & & & 4.61 & \\
\hline \multirow[t]{6}{*}{ Seed dimpling (\%) } & 2010 Sutherland & & & & & & 3.69 & & & 8.85 & & & & & \\
\hline & 2010 Rosthern & & & & & & & 3.62 & & 9.14 & & & & & \\
\hline & 2011 Sutherland & & & & & & & & & 9.02 & & & & & \\
\hline & 2011 Rosthern & & & & & & & & & 4.12 & & & & & \\
\hline & 2012 Sutherland & & & & & & & & & 9.53 & & & & & \\
\hline & 2012 Rosthern & & & & & & & 5.99 & 4.85 & 10.37 & & & & & \\
\hline \multirow[t]{6}{*}{ Seed shape $(1-5)$} & 2010 Sutherland & & & & 3.96 & & & 8.3 & & & & & & 7.87 & \\
\hline & 2010 Rosthern & & & & 6.02 & & & 8.57 & 5.52 & & & & & & \\
\hline & 2011 Sutherland & & & & & & & 4.56 & & & & & 3.68 & & \\
\hline & 2011 Rosthern & & & & & & & 8.29 & & & & & 4.24 & 6.48 & \\
\hline & 2012 Sutherland & & & & & & 4.72 & 3.71 & & & & & & 6.29 & \\
\hline & 2012 Rosthern & & & & & & & 7.65 & & & & & & 8.46 & \\
\hline
\end{tabular}

Values presented in the table represent logarithm of the odds (LOD) of the QTL peak

LG4 and LG7a were identified in four and three of the six trials, respectively (Table 3). The QTLs on all these three linkage groups shared the same linkage group position in at least $50 \%$ of the trials and represented a maximum LOD of 19.5 and explained a phenotypic variance of up to $44.0 \%$ (Table 6 ).

QTLs for seed starch concentration For seed starch concentration, multiple QTLs were identified on LG2b and LG4a of PR-02, and LG1a, LG3b, LG3c and LG7b of PR-07 (Tables 2 and 3). In PR-02, the QTLs on LG2b represented the same linkage group regions in two of the three trials tested with an LOD of 5.5 and $21.0 \%$ of phenotypic variance explained (Table 5). In PR-07, QTLs identified on LG1a, LG3b, LG3c and LG7a were significant in repeated trials, and the QTLs shared the linkage group positions in majority of the trials. The maximum LOD value represented by an individual QTL is 8.4 and this QTL on LG7a explained a phenotypic variance of $20.1 \%$ (Table 6).

QTLs for seed iron concentration Based on two phenotypic trials, QTLs for seed iron concentration were identified on four linkage groups of PR-02, while the QTL on LG3b was highly significant in both the trials representing LOD values of 7.6 and 6.3 (Table 2). This QTL has the common linkage group position in both trials and represents a phenotypic variance of 20.7 and 
Table 4 Quantitative trait loci (QTL) identified for multiple traits in PR-15 mapping population

\begin{tabular}{|c|c|c|c|c|c|c|c|c|c|c|c|c|c|c|}
\hline \multirow[t]{2}{*}{ Trait } & \multirow[t]{2}{*}{ Station/year } & \multicolumn{13}{|c|}{ Linkage group } \\
\hline & & LG1a & LG1b & LG1C & LG2a & LG2b & LG3a & LG3b & LG4 & LG5 & LG6a & LG6b & LG7a & LG7b \\
\hline \multirow[t]{4}{*}{ Days to flowering } & 2012 Sutherland & & & & & & & & 3.8 & & & & & \\
\hline & 2012 Rosthern & & & & & & 4.69 & & & 5.21 & 3.52 & & & \\
\hline & 2013 Sutherland & & & & & 4.48 & 4.58 & & & 7.22 & & & & \\
\hline & 2013 Rosthern & & & & & & & & & 3.94 & & & 3.73 & \\
\hline \multirow[t]{5}{*}{ Days to maturity } & 2012 Sutherland & & 3.99 & & & & 3.51 & & & 3.57 & & & & \\
\hline & 2012 Rosthern & & & & & & 4.71 & & & 3.2 & & & & \\
\hline & & & & & & & 3.33 & & & & & & & \\
\hline & 2013 Sutherland & & & & & 4.02 & 3.76 & & & 6.55 & & & 5.01 & \\
\hline & 2013 Rosthern & & & & & & 5.79 & & & 3.64 & & & 5.6 & \\
\hline \multirow[t]{5}{*}{ Plant height (cm) } & 2012 Sutherland & & & & & & 4.35 & & & & & & & \\
\hline & 2012 Rosthern & & & & & & 12.99 & & 5.25 & & & & 5.92 & \\
\hline & 2013 Sutherland & & & & & & 6.06 & & & 3.22 & & & & \\
\hline & & & & & & & 3.47 & & & & & & & \\
\hline & 2013 Rosthern & & & & 5.2 & & 12.94 & & & & & & & \\
\hline \multirow[t]{4}{*}{ Lodging resistance (1-9) } & 2012 Sutherland & & & & & & 9.15 & & & & & & & \\
\hline & 2012 Rosthern & & & & & & 8.83 & & & & & & 3.11 & \\
\hline & 2013 Sutherland & & & & & & & & & & 3.37 & & & \\
\hline & 2013 Rosthern & & & & & 3.7 & & & & & & & & \\
\hline \multirow[t]{5}{*}{ Yield $\left(\mathrm{g} / \mathrm{m}^{2}\right)$} & 2012 Sutherland & & 3.39 & & & & 5.45 & & & & & & & \\
\hline & 2012 Rosthern & & 3.16 & & & & 4.1 & & 9.06 & & & & & \\
\hline & 2013 Sutherland & & & & & & 4.67 & & & & & & & \\
\hline & & & & & & & 3.11 & & & & & & & \\
\hline & 2013 Rosthern & & & & & & 4.77 & & & & & & & \\
\hline \multirow[t]{6}{*}{ Seed phytate conc. (ppm) } & 2012 Sutherland & & & & & & 3.52 & & & 10.59 & 5.09 & & & \\
\hline & & & & & & & & & & & 6.93 & & & \\
\hline & 2012 Rosthern & & & & & & & & & 12.48 & & & & \\
\hline & 2013 Sutherland & & & & & & 4.08 & & & 11.37 & 4.53 & & & \\
\hline & & & & & & & & & & & 6.03 & & & \\
\hline & 2013 Rosthern & & & & & & & & & 6.69 & & & & \\
\hline
\end{tabular}

Values presented in the table represent logarithm of the odds (LOD) of the QTL peak

26.7\% (Table 5). In comparison, of the QTLs identified on six linkage groups of PR-07, the QTLs on LG3b were significant in all of the six trials tested (Table 3). QTLs on this linkage group shared the linkage group position in four of the six trials and represented a maximum LOD of 10.1 and phenotypic variance of $35.5 \%$ (Table 6).

QTLs for seed selenium concentration QTLs were identified on three linkage groups of PR-02 based on two phenotypic trials, of which LG7 represented QTLs in both the trials within the same linkage group region and explained a phenotypic variance of up to $15.0 \%$ (Tables 2 and 5). In PR-7, QTLs were identified on LG4 and LG5b in two of the six trials (Table 3). The QTL on LG5b has the maximum LOD value of 4.5 and explained $17.1 \%$ of the phenotypic variance.

QTLs for seed zinc concentration Four QTLs were identified one each on LG1a and LG3b, and two on LG6 of PR-02 in one of the two trials tested (Table 2). The QTL on LG3b was highly significant with an LOD value of 13.7 and $25.8 \%$ of phenotypic variance (Table 5). In comparison, the most significant QTLs for seed zinc concentration in PR-07 were also located on LG3b. One QTL on this linkage group positioned in the same region in three trials had an average LOD value of 15.5 and explained $42.7 \%$ of 


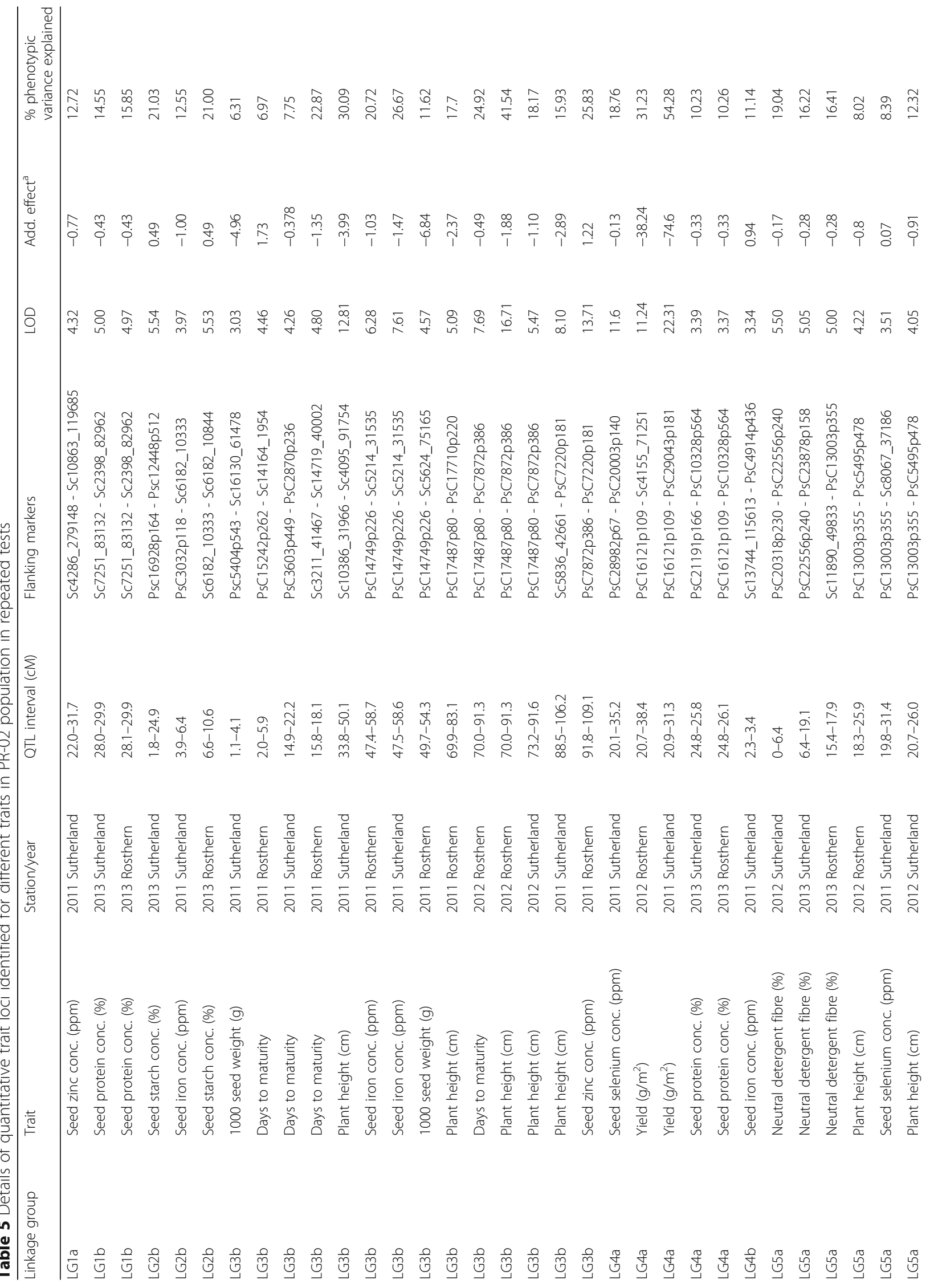




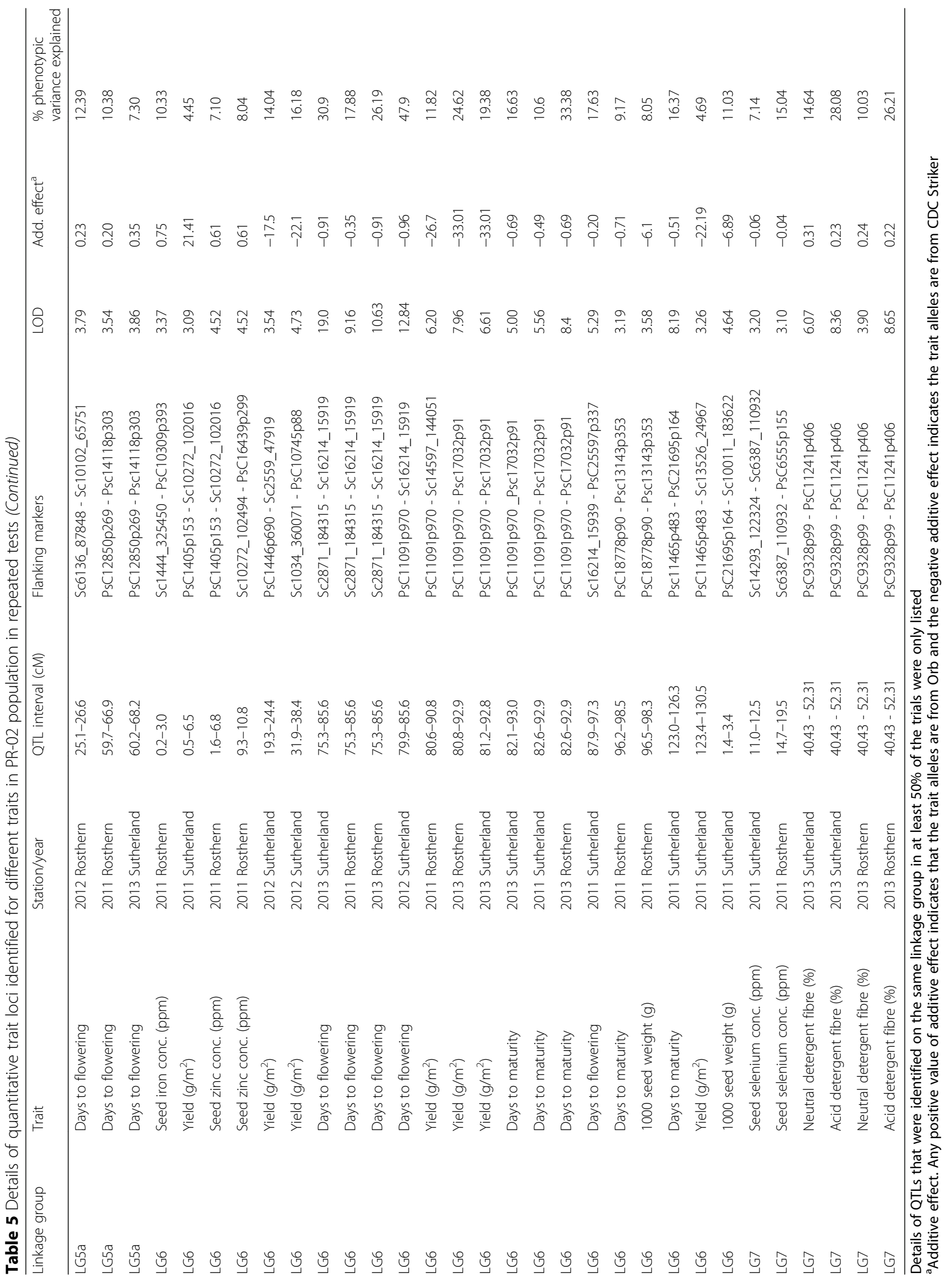




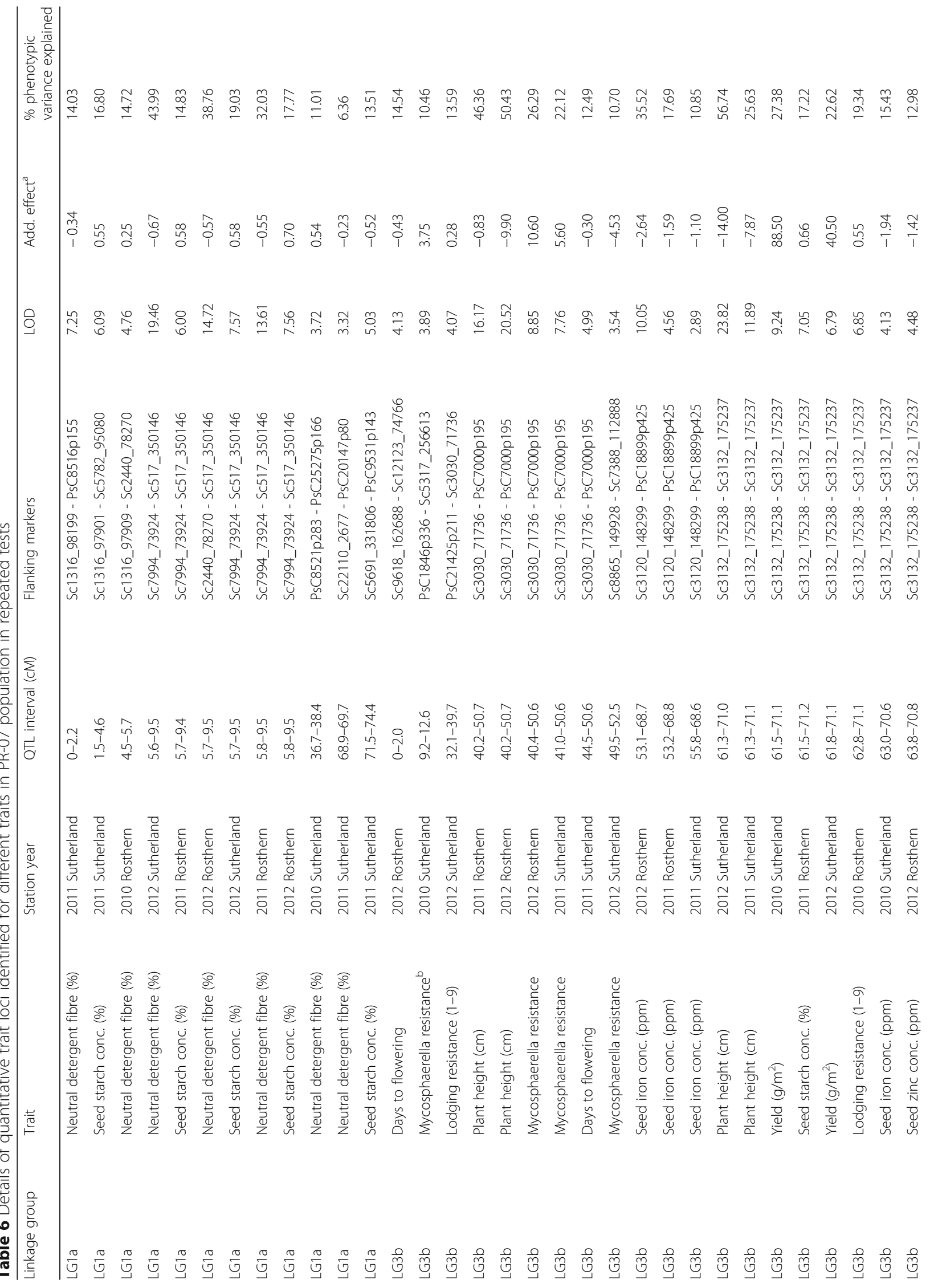




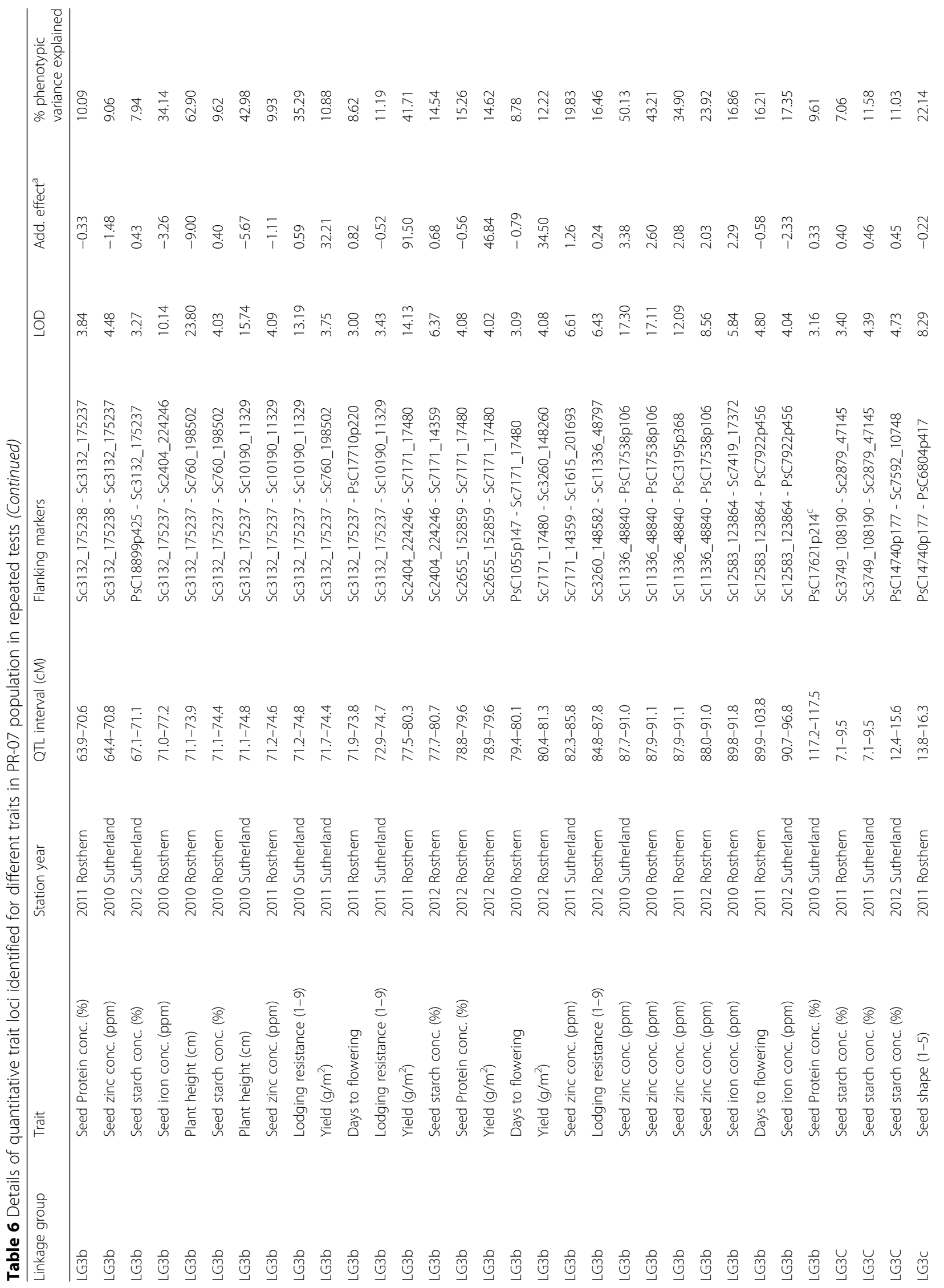




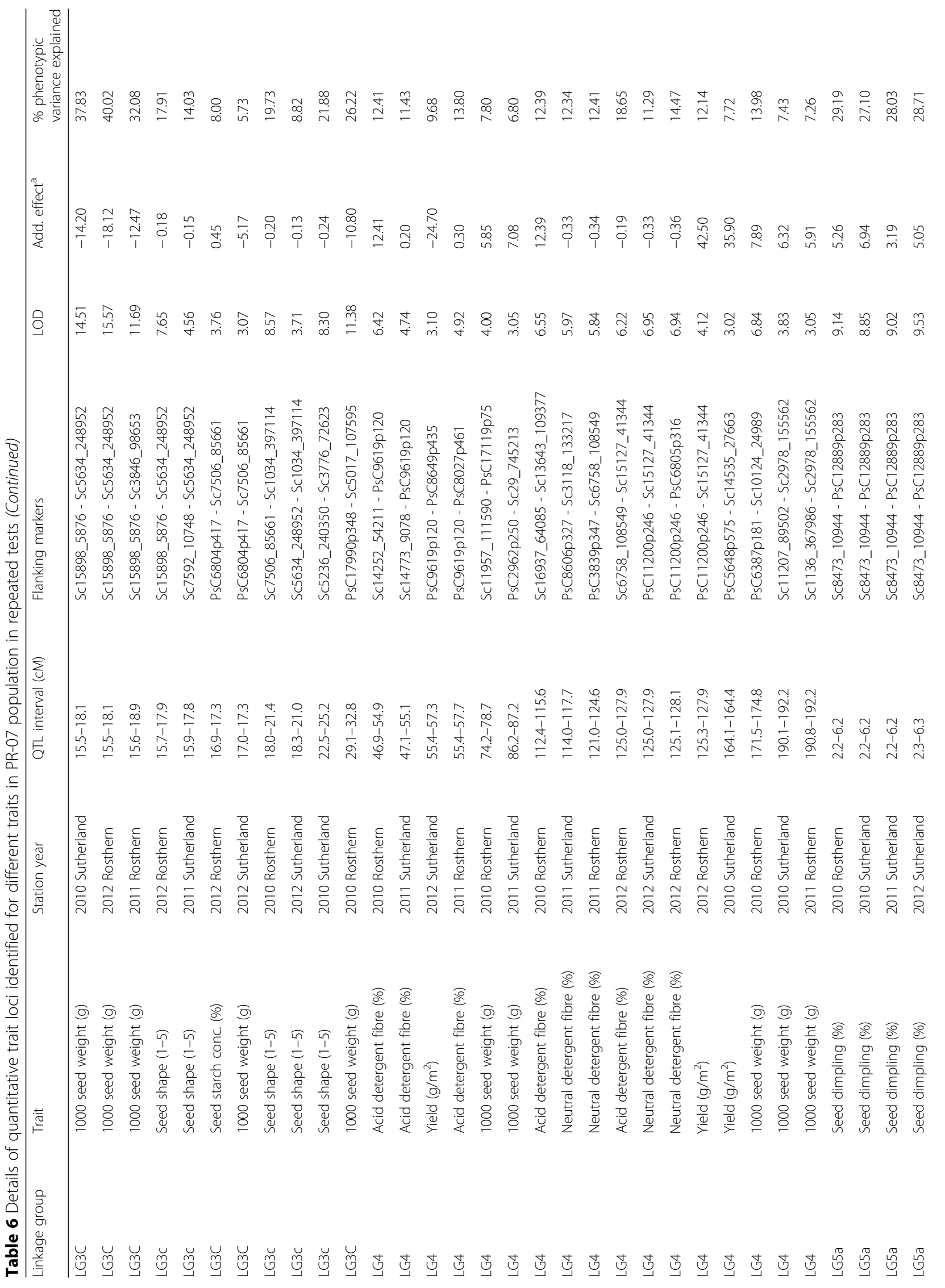




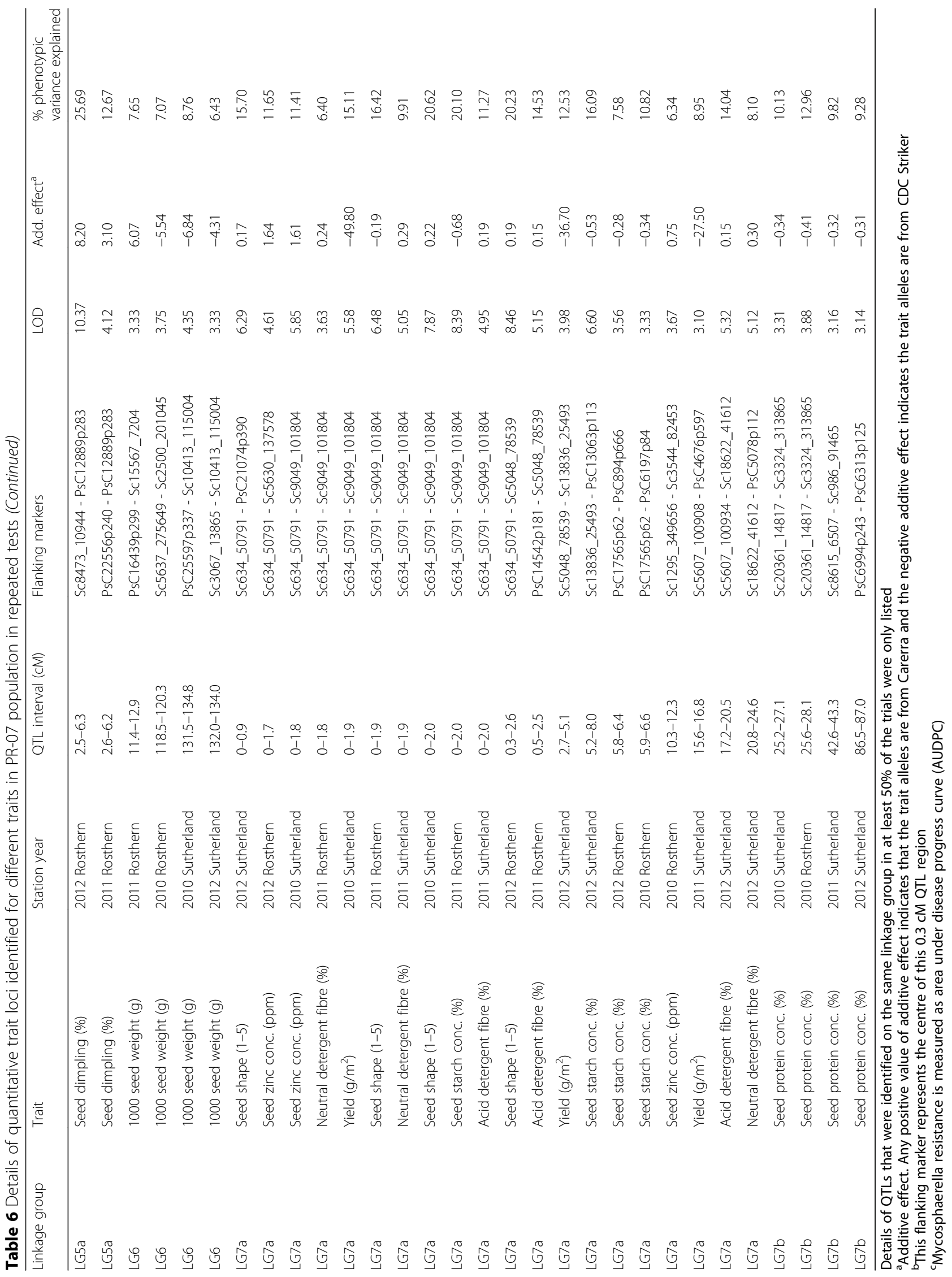




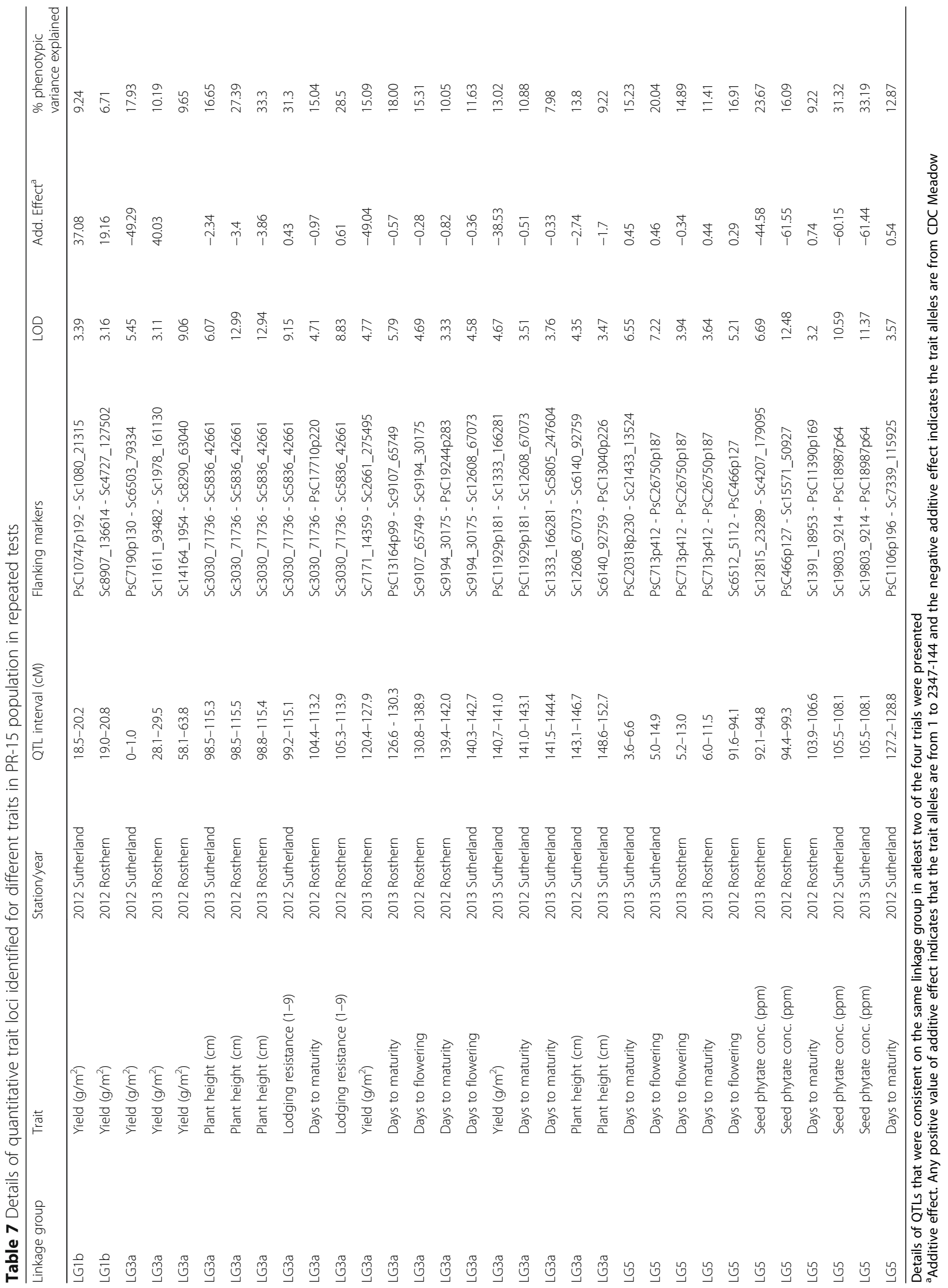


the phenotypic variance (Table 6). QTLs were also identified on LG7a in repeated trials with a maximum LOD of 5.9 and $11.7 \%$ of phenotypic variance explained (Table 6).

QTLs for seed dimpling In PR-07, QTLs for seed dimpling were identified on four linkage groups with the QTL on LG5a being consistent in all six trials (Table 3). This QTL was mapped in the same linakge group position in all trials. The LOD and percent phenotypic variance explained by this QTL ranged from 4.1 to 10.4 and 12.7 to 29.2 , respectively (Table 6).

QTLs for seed shape In PR-07, 16 QTLs located on six linkage groups were identified for seed shape. The QTLs on LG3c were identified in all six trials, while the QTLs on LG7a were identified in four of the six trials (Table 3). The maximum LOD of QTLs on LG3C was 8.6, and the maximum phenotypic variance explained was $22.1 \%$. The four QTLs identified on LG7a shared the linkage group position and the LOD and percent phenotypic variance explained ranged from 6.3 to 8.5 , and 15.7 to 20.6, respectively (Table 6).

QTLs for seed phytate concentration QTLs for seed phytate concentration were mapped in PR-15. QTLs for this trait were identified on three linkage groups, LG3a, LG5 and LG6a, of which the QTL on LG5 was identified in all four trials tested in two locations (Table 4). The four QTLs were positioned in two chromosome regions, with two trials from each location sharing the same region. The LOD values of these QTLs ranged from 6.7 to 12.5 and explained a phenotypic variance of 16.1 to $33.2 \%$ (Table 7).

\section{Discussion}

Precise phenotyping is critical for accurate identification of marker trait association and presence of QTL [5]. This research was based on substantial sets of phenotypic data collected in three pea RIL populations. Phenotypic data arose from field trials which were managed under conditions typical of field pea production in western Canada. Field trials are superior to indoor trials in terms of their direct relevance to plant breeding and subsequent commercial applications. Agronomic traits (days to flower, days to maturity, plant height, lodging score, and grain yield) were assessed at four to six station/years, with two biological replications at each station/year. All field trials had low coefficient of variation for grain yield, and average to above-average mean grain yield indicating their reliability for use in QTL analyses. Relevant seed quality assessments (seed macroand micro-nutrient concentration, seed weight, seed dimpling, and seed shape), including phytate concentration in the case of PR-15, were collected and in all cases useful variation was noted. The most significant trait associations observed among the three RIL populations were between days to flowering and days to maturity, days to maturity and yield, and Mycosphaerella blight severity and lodging.

In this research, we identified QTLs for many important traits for pea breeding, based on extensive phenotyping in field trials and high density genetic linkage maps based on GBS and Illumina GoldenGate array genotyping. Some of the traits evaluated in this study are highly quantitative in nature, and are important for pea breeding. Some of the QTLs identified for individual traits were also compared between the mapping populations.

We used the GBS protocol as described by Elshire et al. [13] to genotype the pea mapping populations because of its potential for SNP discovery across the entire genome and the availability of a reference draft genome provided by the International Pea Genome Consortium to facilitate read alignment and SNP calling. GBS has been successfully used in many different crops to score co-dominant SNP markers across the genome and to generate high density genetic linkage maps [35]. Based on whole genome sequencing of four pea lines, Boutet et al. [19] identified 419,024 SNPs and a subset of 64,754 SNPs were genotyped by sequencing of RILs of the cross Baccara/PI180693, thus indicating the potential of sequence based genotyping methods for simultaneous genotyping of a number of SNPs in pea. In our study, GBS was successful in identification of $>25,000$ SNPs in each mapping population, and after filtering 2234, 3389 and 3541 SNP markers were used for genetic linkage map construction in PR-02, PR-07 and PR-15 mapping populations, respectively. In a similar study, using ApekI restriction digestion based GBS, Ma et al. [36] identified 1609 high quality SNPs in a pea RIL population derived from Aragorn x Kiflica. To improve the quality of the genetic linkage maps, all SNP markers with $>15 \%$ missing data were omitted from map construction, though some important SNPs might have been eliminated. Liu et al. [37] suggested utilization of SNPs with $<20 \%$ missing data without imputation to improve the data quality of GBS genotyping. The SNP markers genotyped by GBS were anchored with the existing SNP markers genotyped in the same populations [10] for assignment of linkage groups as well as generation of dense linkage maps. The average distance between the mapped loci was $1.57 \mathrm{cM}$, and the identified GBS markers were distributed across the seven chromosomes of pea. The dense genetic linkage maps developed in the current study will facilitate further fine-mapping of the identified QTLs for agronomic and seed nutritional traits.

The genetic linkage maps developed in this study were used to identify QTLs for multiple traits in multiple 
environments. The phenotypic data from each station/ year were used independently for identification of QTLs and their consistency across environments. In interpreting the results for identification of reliable trait-linked markers, QTLs which were identified on the same linkage groups in repeated trials were considered, and the next level of comparison was made through comparison of QTL positions in repeated trials. Overall, 375 QTLs were identified for various traits including days to flowering, days to maturity, plant height, Mycosphaerella blight resistance, lodging resistance, seed mineral concentration, starch and fibre concentration, seed weight and grain yield, known to be a highly complex trait. Highly significant and reproducible QTLs were identified for plant height, lodging resistance, yield and seed iron concentration in more than one population.

Although flowering time is a quantitative trait controlled by multiple genes, in pea HIGH RESPONSE TO PHOTOPERIOD (HR), an ortholog of EARLY FLOWERING 3 (ELF3), has been identified as a gene involved in Circadian clock function, which controls a significant proportion of flowering time variation in global pea germplasm [38]. Henaut et al. [39] confirmed the association of the $H R$ locus with QTL for flowering time and the co-localization of this locus with a major QTL affecting winter frost tolerance. Vanhala et al. [40] reported that in the absence of HR, flowering time in a collection of pea accessions was affected by the LATE FLOWERING (LF) gene, and positively correlated with the length of the growing season in the region of origin of the accession. In the current study, the major QTL for flowering time was localized on LG6 in PR-02. This QTL was identified in five of the six field trials tested, shared overlapping linkage group positions, and explained phenotypic variance of up to $47.9 \%$. Based on the known linkage between $H R$ locus and flowering time response in pea from previous studies, this QTL on LG6 could be the $H R$ locus. Identification of QTLs for flowering time in PR-07 and PR-15 on different linkage groups could be because of the absence of $H R$ locus in these populations.

Highly significant QTLs for plant height were identified in all three mapping populations. One QTL each on LG3b of PR-02, LG3c of PR-07, and LG3a of PR-15 identified in repeated trials, contributed to a phenotypic variance of $41.5,65.1$ and $33.3 \%$ in the three populations, respectively. Tar'an et al. [22] reported three QTLs related to plant height in a RIL population tested in 11 environments, and the QTLs together explained $65 \%$ of the phenotypic variance. Hamon et al. [41] identified three minor QTLs for plant height in another RIL population and these QTLs were linked to Aphanomyces root rot resistance. Plant height is known to be associated with other traits such as lodging resistance and Mycosphaerella blight resistance. The QTLs identified for plant height in the current study are well suited for MAS in breeding programs as they explain $33-65 \%$ of the phenotypic variance. Similar to the observations in pea, plant height in chickpea was identified as a quantitative trait governed by six QTLs [42].

In pea, improvement of lodging resistance is an important breeding objective to improve air circulation in the canopy as a means of reducing fungal disease development, and to facilitate harvest. Only a few studies have reported QTLs associated with this complex quantitative trait, which is also highly dependent on environmental factors. Tar'an et al. [22] reported two QTLs for lodging resistance which explained $58 \%$ of the phenotypic variance in 11 environments tested. In the current study, we identified a major QTL for lodging resistance on linkage group 3c of PR-07 in the majority of the environments tested and this QTL explained a phenotypic variance of up to $35.3 \%$. In PR-15 the major QTL was located on LG3a and shared the linkage group region in two of the four environments tested and explained a phenotypic variance of 31.3 and $28.5 \%$. A major QTL for lodging resistance in a pea RIL population derived from Delta x RER which explained $49.9 \%$ of the phenotypic variance was also located on linkage group 3 [43]. The major QTLs for lodging resistance in both PR-02 and PR-07 overlapped with the QTLs for plant height identified in these populations. Tar'an et al. [22] also reported that QTLs associated with lodging susceptibility in pea were also associated with plant height.

Mycosphaerella blight resistance is another complex quantitative trait important for pea breeding. Lodging susceptibility is known to increase the severity of Mycosphaerella blight [44] and Mycosphaerella resistance QTLs are known to be associated with lodging resistance [17]. We have identified QTLs for Mycosphaerella resistance on LG3b and LG4 in PR-07. These QTLs explained phenotypic variation of $10.5-26.3 \%$. The position of the QTLs within these linkage groups varied from one trial to another with the exception of one QTL on LG4 identified in two trials, thus indicating the effect of environment on disease resistance. Using an interspecific pea RIL population, Jha et al. [30] identified QTLs for Mycosphaerella resistance on LGIII and LGIV in repeated field trials. Most of the Mycosphaerella resistance QTLs identified in other mapping populations were also located on LGIII $[45,46]$.

Grain yield is a complex quantitative trait and we have identified multiple QTLs for grain yield in different mapping populations. The QTLs on LG4a and LG6 in PR-02, LG3c and LG7b of PR-07, and LG1b of PR-15 were identified in repeated trials and explained a phenotypic variance of 6.7 to $54.2 \%$. The QTL on LG3c of PR-07 is of particular importance as it was identified in five of the six trials and explained a phenotypic variance of 13.3 to $21.6 \%$. Several QTLs for grain yield have been 
reported earlier. Tar'an et al. [47] identified QTLs for grain yield which together explained 39\% of the phenotypic variance and the major QTLs were located on LGII. Krajewski et al. [48] identified multiple QTLs for grain yield in pea. In their study, the QTLs were identified on different linkage groups, while the major QTLs were located on LG5, with minor QTLs on LG2. Since grain yield is affected by genotype $x$ environment interactions at both vegetative and reproductive growth stages, variation in the QTLs identified in different mapping populations and different environments is expected. Annicchiarico et al. [49] reported co-localization of SNP markers associated with early flowering and high yield of pea in a genome-wide association study (GWAS). In the current study, we have noted co-localization of QTLs associated with days to flowering and grain yield on LG6 of PR-02, LG3b of PR-07 and LG3a of PR-15.

The effect of days to flowering loci on other traits including yield was determined by using the days to flowering loci as control markers in cofactor analysis. The cofactor analysis altered the LOD scores of QTLs for other traits on the same linkage group from 0 to $35 \%$. For example, in the PR-07 trial at Sutherland in 2011, using days to flowering loci on LG3b as control markers did not alter the LOD score of Mycosphaerella blight severity QTL on the same linkage group, increased the LOD of plant height QTL from 11.90 to 17.00 , and decreased the LOD of other QTLs including yield from 3.75 to $3.51,1000$ seed weight from 4.97 to 3.59 , ADF from 10.1 to 6.65 , NDF from 7.44 to 5.33 , seed zinc concentration from 6.61 to 4.6 .

QTLs for other traits including fiber and starch concentration, seed mineral concentration, seed phytate concentration of mature pea seeds were also identified in this study. Some of these QTLs were highly significant and identified in repeated trials, and thus have potential for MAS in pea breeding. For example, the QTL for seed zinc concentration identified on LG3c of PR-07 was identified in four of the six trials and explained a phenotypic variance of 12.3 to $43.2 \%$. Ma et al. [36] reported that the QTL with highest explanation of phenotypic variance for seed zinc concentration in a mapping population derived from Aragorn $x$ Kiflica tested in two different locations was also located on LG3. Shunmugam et al. [50] also reported a major QTL for seed phytate concentration in pea on LG5, and this QTL was confirmed here using an expanded set of markers.

\section{Conclusions}

The current study has identified many QTLs for quantitative traits in pea using GBS resources and dense genetic linkage maps. QTLs for flowering time, plant height and lodging resistance were identified consistently in field trials. There is a potential for fine mapping these QTLs, identification of trait-related genes using the current QTL information, and for using the marker information for MAS in breeding programs. The highly significant and reproducible QTLs identified for days to flowering $\left(\mathrm{PV}_{\max }=47.9 \%\right)$, plant height $\left(\mathrm{PV}_{\max }=65.1 \%\right)$, lodging resistance $\left(\mathrm{PV}_{\max }=35.3 \%\right)$, grain yield $\left(\mathrm{PV}_{\max }=54.2 \%\right)$, seed iron concentration $\left(\mathrm{PV}_{\max }=27.4 \%\right)$, and seed zinc concentration $\left(\mathrm{PV}_{\max }=43.2 \%\right)$ can be used for immediate breeding applications. We are in the process of converting the SNP markers flanking the identified QTL regions for these traits into simple assays, and validating the markers using a genome wide association study (GWAS) panel of 175 genotypes which were phenotyped in multi-location, multi-year replicated field trials.

\section{Additional files}

Additional file 1: Minimum, maximum and mean values of phenotypic traits measured in the parents (Orb and CDC Striker) and the PR-02 population. (XLS $13 \mathrm{~kb}$ )

Additional file 2: Minimum, maximum and mean values of phenotypic traits measured in the parents (Carrera and CDC Striker) and the PR-07 population. (XLS $17 \mathrm{~kb}$ )

Additional file 3: Minimum, maximum and mean values of phenotypic traits measured in the parents (1-2347-144 and CDC Meadow) and the PR-15 population. (XLS $11 \mathrm{~kb}$ )

Additional file 4: Combined correlation eoefficients between phenotypes measured in PR-02 RIL population in six trials. (XLS 10 kb)

Additional file 5: Combined correlation eoefficients between phenotypes measured in PR-07 RIL population. (XLS 13 kb)

Additional file 6: Combined correlation eoefficients between phenotypes measured in PR-15 RIL populations. (XLS 9 kb)

\section{Abbreviations}

DTF: Days to Flowering; DTM: Days to Maturity; GBS: Genotyping-BySequencing; GWAS: Genome-wide Association Study; MAS: Marker Assisted Selection; NGS: Next Generation Sequencing; QTL: Quantitative Trait Loci; SNP: Single Nucleotide Polymorphism; SSR: Simple Sequence Repeats

\section{Acknowledgements}

The financial support of the Saskatchewan Pulse Growers, Saskatchewan Ministry of Agriculture, Western Grains Research Foundation, Natural Sciences and Engineering Research Council of Canada, and the technical support of the pulse crop breeding, pathology, and crop quality staff at the Crop Development Centre, University of Saskatchewan are gratefully acknowledged. Use of the draft pea genome sequence made available by the international consortium for pea genome sequencing is also appreciated.

\section{Funding}

This research was funded by the Saskatchewan Pulse Growers, Saskatchewan Ministry of Agriculture, Western Grains Research Foundation, and Natural Sciences and Engineering Research Council of Canada.

\section{Availability of data and materials}

The mapping populations used in this study are available for research purposes upon written permission from the corresponding author.

\section{Authors' contributions}

TW initiated the project. TW, BT and KKG designed the experiments. KKG conducted genotyping of the mapping populations, linkage analysis, and performed data analysis for QTL identification. KKG wrote the manuscript with input from TW. AS, YL, and ASKS conducted field phenotyping of PR-02, 
PR-07 and PR-15, respectively. MD and KD contributed to analysis of the phenotypic data. GA conducted phenotyping of mapping populations for macro- and micro-nutrients concentration. CC and RL contributed to bioinformatics and GBS SNP allele calling. All authors read and approved the final manuscript.

\section{Ethics approval and consent to participate}

Not applicable

\section{Consent for publication}

Not applicable

\section{Competing interests}

The authors declare that they have no competing interests.

\section{Publisher's Note}

Springer Nature remains neutral with regard to jurisdictional claims in published maps and institutional affiliations.

\section{Author details}

${ }^{1}$ Crop Development Centre, Department of Plant Sciences, 51 Campus Drive, University of Saskatchewan, Saskatoon, SK, Canada. ${ }^{2} \mathrm{CHS}$, Inc, 220 Clement Ave., Grandin, ND 58038, USA. ${ }^{3}$ Agriculture and Agri-Food Canada, London Research and Development centre, 1391 Sandford Street, London, ON N5V 4T3, Canada. ${ }^{4}$ National Research Council Canada, 110 Gymnasium Place, Saskatoon, SK S7N 0W9, Canada. ${ }^{5}$ AgriGenome Labs Pvt Ltd., BTIC, MN iHub, Genome Valley, Shamirpet, Hyderabad 500 078, India.

Received: 2 April 2018 Accepted: 20 July 2018

Published online: 16 August 2018

\section{References}

1. Burstin J, Gallardo K, Mir RR, Varshney RK, Duc G. Improving protein content and nutrition quality. In: Pratap A, Kumar J, editors. Biology and breeding of food legumes. Wallingford, CT: CAB International; 2011. p. 314-28.

2. Tayeh N, Aubert G, Pilet-Nayel M-L, Lejeune-Henaut I, Warkentin TD, Burstin J. Genomic tools in pea breeding programs: status and perspectives. Front Plant Sci. 2015;6:1037.

3. Warkentin TD, Smykal P, Coyne CJ, Weeden N, Domoney C, Bing D, et al Pea (Pisum sativum L.). In: De Ron AM, editor. Grain Legumes. New York: Springer; 2015. p. 37-83

4. Vignesh M, Shanmugavadivel PS, Kokiladevi E. Molecular markers in pea breeding - a review. Agri Reviews. 2011;32(3):183-92.

5. Smýkal P, Aubert G, Burstin J, Coyne C, Ellis N, Flavell AJ, et al. Pea (Pisum sativum L.) in the genomic era. Agronomy. 2012;2(2):74-115.

6. Lavaud C, Lesne A, Piriou C, Le Roy G, Boutet G, Moussart A, et al. Validation of QTL for resistance to Aphanomyces euteiches in different pea genetic backgrounds using near-isogenic lines. Theor Appl Genet. 2015;128(11): 2273-88.

7. Ott J, Wang J, Leal SM. Genetic linkage analysis in the age of wholegenome sequencing. Nature Rev Genet. 2015;16(5):275-84.

8. Varshney RK, Terauchi R, McCouch SR. Harvesting the promising fruits of genomics: applying genome sequencing technologies to crop breeding PLoS Biol. 2014;12(6):e1001883.

9. Zhu Y, Chen K, Mi X, Chen T, Ali J, Ye G, et al. Identification and fine mapping of a stably expressed QTL for cold tolerance at the booting stage using an interconnected breeding population in rice. PLoS One. 2015;10(12):e0145704.

10. Sindhu A, Ramsay L, Sanderson LA, Stonehouse R, Li R, Condie J, et al. Gene-based SNP discovery and genetic mapping in pea. Theor Appl Genet. 2014;127(10):2225-41.

11. Bordat A, Savois V, Nicolas M, Salse J, Chauveau A, Bourgeois M, et al. Translational genomics in legumes allowed placing in silico 5460 unigenes on the pea functional map and identified candidate genes in Pisum sativum L. G3-Genes, Genomes, Genetics (Bethesda). 2011;1(2):93-103.

12. Tayeh N, Aluome C, Falque M, Jacquin F, Klein A. Chauveau, a, et al. development of two major resources for pea genomics: the GenoPea 13.2K SNP Array and a high density, high resolution consensus genetic map. Plant J. 2015;84(6):1257-73.
13. Elshire RJ, Glaubitz JC, Sun Q, Poland JA, Kawamoto K, Buckler ES, Mitchell SE. A robust, simple genotyping-by-sequencing (GBS) approach for high diversity species. PLoS One. 2011;6(5):e19379.

14. Celik I, Gurbuz N, Uncu AT, Frary A, Doganlar S. Genome-wide SNP discovery and QTL mapping for fruit quality traits in inbred backcross lines (IBLs) of Solanum pimpinellifolium using genotyping by sequencing. BMC Genomics. 2017;18:1

15. Lee J, Izzah NK, Choi BS, Joh HJ, Lee SC, Perumal S, et al. Genotyping-bysequencing map permits identification of clubroot resistance QTLs and revision of the reference genome assembly in cabbage (Brassica oleracea L.). DNA Res. 2016:23(1):29-41.

16. Saxena RK, Singh VK, Kale SM, Tathineni R, Parupalli S, Kumar V, et al. Construction of genotyping-by-sequencing based high-density genetic maps and QTL mapping for fusarium wilt resistance in pigeonpea. Sci Rep. 2017;7(1):1911.

17. Jha AB, Gali KK, Tar'an B, Warkentin TD. Fine mapping of QTLs for Ascochyta blight resistance in pea using heterogeneous inbred families. Front Plant Sci. 2017;8:765.

18. Huang S, Gali KK, Tar'an B, Warkentin TD, Bueckert RA. 2017. Pea phenology: crop potential in a warming environment. Crop Sci. 2017:57(3):1540-51.

19. Boutet G, Carvalho SA, Falque M, Peterlongo P, Lhuillier E, Bouchez O, et al. SNP discovery and genetic mapping using genotyping by sequencing of whole genome genomic DNA from a pea RIL population. BMC Genomics. 2016;17:121.

20. Morrell PL, Buckler ES, Ross-lbarra J. Crop genomics: advances and applications. Nat Rev Genet. 2012;13(2):85-96.

21. Verhoeven KJF, Casella G, Mclntyre LM. Epistasis: obstacle or advantage for mapping complex traits? PLoS One. 2010;5(8):e12264

22. Tar'an B, Warkentin T, Somers DJ, Miranda D, Vandenberg A, Blade S, et al, Quantitative trait loci for lodging resistance, plant height and partial resistance to Mycosphaerella blight in field pea (Pisum sativum L.). Theor. Appl. Genet. 2003;107(8):1482-91.

23. Warkentin T, Vandenberg A, Banniza S, Slinkard A. CDC Striker field plea. Can J Plant Sci. 2004;84(1):239-40.

24. Warkentin T, Vandenberg A, Tar'an B, Banniza S, Barlow B, Ife S. CDC meadow field pea. Can J Plant Sci. 2007;87(4):909-10.

25. Warkentin TD, Delgerjav O, Arganosa G, Rehman AU, Bett KE, Anbessa Y, et al. Development and characterization of low-phytate pea. Crop Sci. 2012;52(1):74-8.

26. Kosambi DD. The estimation of map distances from recombination values. Ann Eugenics. 1943;12:172-5.

27. Wu Y, Bhat PR, Close TJ, Lonardi S. Efficient and accurate construction of genetic linkage maps from the minimum spanning tree of a graph. PLoS Genet. 2008:4(10):e1000212.

28. Diapari M, Sindhu A, Warkentin TD, Bett KE, Ramsay L, Sharpe AG, Tar'an B. Population structure and marker-trait association studies of iron, zinc and selenium concentration in seed of field pea (Pisum sativum L.). Mol Breeding. 2015:35:30. https://doi.org/10.1007/s11032-015-0252-2.

29. Arganosa GC, Warkentin TD, Racz VJ, Blade S, Hsu H, Philips C. Prediction of crude protein content in field peas grown in Saskatchewan using near infrared reflectance spectroscopy. Can J Plant Sci. 2006:86:157-9.

30. Jha AB, Tar'an B, Stonehouse R, Warkentin TD. Identification of QTLS associated with improved resistance to Ascochyta blight in an interspecific pea recombinant inbred line population. Crop Sci. 2016;56:2926-39.

31. Ubayasena K, Bett K, Tar'an B, Warkentin TD. Genetic control and identification of QTLs associated with visual quality traits of field pea (Pisum sativum L.). Genome. 2011;54:261-72.

32. Shapiro SS, Wilk MB. An analysis of variance test for normality (complete samples). Biometrika. 1965;52:591-611.

33. Wang S, Basten CJ, Zeng ZB: Windows QTL Cartographer 2.5. http://statgen ncsu.edu/qtlcart/WQTLCart.htm (2007). Accessed 23 Mar 2018.

34. Gawalko E, Garrett RG, Warkentin TD, Wang N, Richter A. Trace elements in Canadian peas: a grain safety assurance perspective. Food Addit Contam. 2009;26:1002-12.

35. Yang Z, Chen Z, Peng Z, Yu Y, Liao M, Wei S. Development of a highdensity linkage map and mapping of the three-pistil gene (Pis 1) in wheat using GBS markers. BMC Genomics. 2017;18:567.

36. Ma Y, Coyne CJ, Grusak MA, Mazourek M, Cheng P, Main D, RJ MG. Genome-wide SNP identification, linkage map construction and QTL 
mapping for seed mineral concentrations and contents in pea (Pisum sativum L.). BMC Plant Biol. 2017;17:43.

37. Liu H, Bayer M, Druka A, Ressell JR, Hackett CA, Poland J, et al. An evaluation of genotyping by sequencing (GBS) to map the Breviaristatum-e (ari-e) locus in cultivated barley. BMC Genomics. 2014;15:104.

38. Weller JL, Liew LC, Hecht VF, Rajandran V, Laurie RE, Ridge S, et al. A conserved molecular basis for photoperiod adaptation in two temperate legumes. PNAS. 2012;109(51):21158-63.

39. Henaut L, Hanocq E, Bethencourt L, Fontaine V, Delbreil B, Morin J, et al. The flowering locus $\mathrm{Hr}$ colocalizes with a major QTL affecting winter frost tolerance in Pisum sativum L. Theor. Appl. Genet. 2008;116(8):1105-16.

40. Vanhala T, Normann KR, Lundstrom M, Weller JL, Leino MW, Hagenblad J. Flowering time adaption in Swedish landrace pea (Pisum sativum L.). BMC Genet. 2016;17:117.

41. Hamon C, Coyne CJ, McGee RJ, Lesne A. QTL meta-analysis provides a comprehensive view of loci controlling partial resistance to Aphanomycces euteiches in four sources of resistance in pea. BMC Plant Biol. 2013;13:45.

42. Kujur A, Upadhyaya HD, Bajaj D, Gowda CL, Sharma S, Tyagi AK, Parida SK. Identification of candidate genes and natural allelic variants for QTLS governing plant height in chickpea. Sci Rep. 2016;6:27968.

43. Smitchger, J.A. Quantitative trait loci associated with lodging, stem strength, yield, and other important agronomic traits in dry field peas. https://zenodo. org/record/840399\#.Wizg-k1hiM8 (2017). Accessed 09 Dec 2017.

44. Wang TF, Gossen BD, Slinkard AE. Lodging increases severity and impact of Mycosphaerella blight on field pea. Can J Plant Sci. 2006;86(3):855-63.

45. Fondevilla S, Almeida NF, Satovic Z, Rubiales D, Patto MCV, Cubero JI, Torres AM. Identification of common genomic regions controlling resistance to Mycosphaerella pinodes, earliness and architectural traits in different pea genetic backgrounds. Euphytica. 2011;182(1):43-52.

46. Prioul-Gervais S, Deniot G, Receveur EM, Frankewitz A, Fourmann M, Rameau C, et al. Candidate genes for quantitative resistance to Ascochyta pinodes in pea (Pisum sativum L.). Theor. Appl. Genet. 2007;114(6):971-84.

47. Tar'an B, Warkentin T, Somers DJ, Miranda D, Vandenberg A, Blade S, Bing D. Identification of quantitative trait loci for grain yield, seed protein concentration and maturity in field pea (Pisum sativum L.). Euphytica. 2004;136(3):297-306.

48. Krajewski P, Bocianowski J, Gawlowska M, Kaczmarek Z, Pniewski T, Swiecicki W, Wolko B. QTL for yield components and protein content: a multienvironment study of two pea (Pisum sativum L.) populations. Euphytica. 2012;183(3):323-36.

49. Annicchiarico P, Nazziacari N, Pecetti L, Romani M, Ferrari B, Wei Y, Brummer EC. GBS-based genomic selection for pea grain yield under severe terminal drought. Plant Genome. 2017;10(2) https://doi.org/10.3835/ plantgenome2016.07.0072.

50. Shunmugam ASK, Liu X, Stonehouse R, Tar'an B, Bett KE, Sharpe AG, Warkentin TD. Mapping seed phytic acid concentration and iron bioavailability in a pea recombinant inbred line population. Crop Sci. 2015;55(2):828-36.

\section{Ready to submit your research? Choose BMC and benefit from:}

- fast, convenient online submission

- thorough peer review by experienced researchers in your field

- rapid publication on acceptance

- support for research data, including large and complex data types

- gold Open Access which fosters wider collaboration and increased citations

- maximum visibility for your research: over $100 \mathrm{M}$ website views per year

At BMC, research is always in progress.

Learn more biomedcentral.com/submissions 